\title{
OPEN Persistent meanders and eddies lead to quasi-steady Lagrangian transport patterns in a weak western boundary current
}

\author{
M. B. Gouveia $\mathbb{D}^{1}$, R. Duran $\mathbb{D}^{2,3 凶}$, J. A. Lorenzzetti $\mathbb{D}^{1}$, A. T. Assireu $\mathbb{D}^{4}$, R. Toste $\mathbb{D}^{5}$, \\ L. P. de F. Assad ${ }^{5}$ \& D. F. M. Gherardi ${ }^{1}$
}

The Brazil Current (BC) is a weak western boundary current flowing along the Southwestern Atlantic Ocean. It is frequently described as a flow with intense mesoscale activity and relatively low volume transport between 5.0 and $10.0 \mathrm{~Sv}$. We use a 13 -year eddy-resolving primitive-equation simulation to show that the presence of persistent meanders and eddies leads to characteristic quasi-steady Lagrangian transport patterns, aptly extracted through climatological Lagrangian Coherent Structures (cLCS). The CLCS position the surface expression of the BC core along the $2000-\mathrm{m}$ isobath, in excellent visual agreement with high resolution satellite sea-surface temperature and the model Eulerian mean velocity. The cLCS deformation pattern also responds to zonally persistent cross-shelf SSH transition from positive (high) values near coastline to low (negative) values between 200- and 2000-m and back to positive (high) offshore from the 2000-m isobath. Zonally-paired cyclonic and anticyclonic structures are embedded in this transition, also causing the cLCS to deform into chevrons. An efficient transport barrier is identified close to the 200-m isobath confirmed by limited inshore movement of drogued drifters and accurately indicated by an along slope maxima of climatological strength of attraction. We also show that the persistent cyclonic and anticyclonic structures may induce localized cross-shelf transport. Regions of low climatological strength of attraction coincide with large shelves and with stagnant synthetic trajectories. We also show that cLCS accurately depict trajectories initiated at the location of Chevron's spill (November 2011) as compared to synthetic and satellite-tracked trajectories, and the outline of the oil from that accident. There is also an agreement between the large-scale oil slicks reaching the Brazilian beaches (from August 2019 to February 2020) and the strength of climatological attraction at the coast. Our work also clarifies the influence of persistent mesoscale structures on the regional circulation. The identification and quantitative description of climatological Lagrangian coherent structures is expected to improve the effectiveness of future emergency response to oil spills, contingency planning, rescue operations, larval and fish connectivity assessment, drifter launch strategies, waste pollutant and marine debris dispersion and destination.

Subtropical western boundary currents (WBC) are one of the main contributors to the meridional ocean transport of heat and salt ${ }^{1-3}$. They are generally depicted as continuous surface flows and their intensity and persistence are considered as a dynamic barrier for cross-flow transport ${ }^{4}$, influencing the pathway of pollutants and fish larvae ${ }^{5-9}$. However, the Brazil Current (BC) is considered a weak WBC in the Southwestern Atlantic Ocean $(\mathrm{SWA})^{10}$. The $\mathrm{BC}$ transports a relatively small volume (values ranging 4-6.5 Sv) ${ }^{11}$ of water southward in the upper $520 \mathrm{~m}^{12}$. Strong mesoscale activity develops in the vicinity of the BC, mainly near $22 \mathrm{~S}$, with large frontal meanders and eddies ${ }^{13}$. Despite being weak relative to other western boundary currents, the BC has been found to exert significant control over Lagrangian transport ${ }^{14}$. In this paper we examine persistent Lagrangian transport patterns in a WBC with persistent meanders and eddies.

${ }^{1}$ Division of Remote Sensing, National Institute for Space Research, São José dos Campos 12227-010, Brazil. ${ }^{2}$ National Energy Technology Laboratory, Albany, OR 97321, USA. ${ }^{3}$ Theiss Research, La Jolla, CA 92037, USA. ${ }^{4}$ Natural Resources Institute, Federal University of Itajubá, Itajubá 37500-015, Brazil. ${ }^{5}$ Laboratory for Computational Methods in Engineering, COPPE/UFRJ, Rio de Janeiro 21941-907, Brazil. ${ }^{\square}$ email: r.duran@ theissresearch.org 
In the South Atlantic (SA) as a whole, several studies, and mostly making use of satellite altimeter data, indicate two major regions of very high eddy energy content: first is S/SW tip of Africa in the Agulhas retroflection region (ARR), where a series of Agulhas rings (AR) eddies are generated per year, which tend to migrate W/ WNW into the South Atlantic. However, according to Byrne et al. ${ }^{15}$, these AR lose energy in their westward displacement and rarely reach as far as the $\mathrm{BC}$ region. The second region of high eddy energy is the Brazil-Malvinas Confluence region, centered about $40 \mathrm{~S}$ and $45 \mathrm{~W}$. A third region, albeit of smaller magnitude, is inside our study domain in $\mathrm{BC}$ region and offshore waters ${ }^{16-19}$. Regarding the dynamic characteristics of such mesoscale variability in the SA, most of the observed SLH anomalies in the altimeter data are now believed to be caused by a combination of westward propagating Rossby waves and non-linear eddies which propagate generally towards west with a small northward component ${ }^{20,21}$. In the $\mathrm{BC}$ region, baroclinic instabilities of the $\mathrm{BC}$ are associated with the generation of meandering and eddy shedding ${ }^{22}$.

Ponsoni ${ }^{19}$ has done a spectral analysis of altimeter-based geostrophic velocities obtained in a cross-shore transect of BC region from 200 to $2000-\mathrm{m}$ isobaths centered at $26 \mathrm{~S}$. Two main spectral peaks are evident. One close to yearly period ( 340 days) is associated with the inshore parts of the BC; another peak at about three months period (100 days) dominates at the offshore side waters. This higher frequency band is supposed to be strongly influenced by SHA generated at ARR which propagate westward in a high eddy energy corridor towards the western region of SA and toward our region of study. Additionally, it was conjectured that cases of stronger (weaker) BC current were associated with the presence of anticyclonic (cyclonic) eddies. The landward side of anticyclonic (cyclonic) flowing southward (northward) would increase (decrease or even reverse) the BC flow.

The seasonal variability of eddy kinetic energy (EKE) in the SA has been presented by Scharffenberg and Stammer ${ }^{16}$ who calculated for different oceanic regions basin-wide zonal averages of the annual harmonic EKE. Seasonal variations of EKE in the Tropical and South Atlantic are very significant only in at low latitudes and in the $\mathrm{BMC}$, but go through a minimum of the signal in our study region in the western SA.

The baroclinically unstable nature of the $\mathrm{BC}$ is caused by the presence of the of the Intermediate Western Boundary Current flowing to the north between 800- and 1000-m depth, below the BC, which in the upper 500 $\mathrm{m}$ transports the Tropical Water (TW) and the South Atlantic Central Water to the south ${ }^{13}$. The formation of meanders and eddies can also locally reverse the current flow offshore of the $1000 \mathrm{~m}$ isobath and cause changes in current transport ${ }^{23}$. The intense mesoscale activity along the $\mathrm{BC}$, from its origin in the bifurcation of the South Equatorial Current down to the Brazil-Malvinas confluence region, includes recurrent or semi-permanent meanders, cyclonic and anticyclonic structures, and eddies ${ }^{24,25}$.

The method to compute climatological Lagrangian coherent structures (cLCS) was developed recently by Duran et al. ${ }^{26}$ and has been used to extract important Lagrangian transport patterns from large velocity time series. Pattern identification include (1) isolated regions where trajectories are unlikely to leave or enter; (2) regions that attract nearby parcels of water and therefore are more susceptible to pollution impacts; and (3) recurrent transport patterns. Some recent studies have shown the relevance of cLCS. Gough et al. ${ }^{27}$ showed the efficacy of some of the cLCS as transport barriers by using synthetic drifters advected by the instantaneous model velocities and by using 3207 satellite-tracked drifter trajectories spanning over two decades (1994-2016). Maslo et al. ${ }^{28}$ showed that cLCS were efficient in identifying predominant transport patterns in the deep $(\approx 1500 \mathrm{~m})$ Gulf of Mexico, as determined by RAFOS floats and synthetic drifter trajectories.

To compute cLCS, Gough et al. ${ }^{27}$ and Maslo et al. ${ }^{28}$ used a free-run simulation performed with NEMO (Nucleus for European Modelling of the Ocean) and ROMS (Regional Ocean Modeling System), respectively, while Duran et al. ${ }^{26}$ used an operational HyCOM (Hybrid Coordinate Ocean Model) simulation. Thus, in combination, these three papers show that CLCS are robust in bypassing the variability inherent to geophysical flows, while accurately identifying predominant transport patterns. Searching for structures that are able to bypass the chaotic nature of transport while extracting predominant, and important, transport patterns from long velocity time series was the motivation behind the development of $\mathrm{CLCS}^{26}$.

In this paper we show cLCS' capability in extracting the predominant circulation from another free-run numerical simulation, in the distinct setting of a WBC, characterized by the presence of persistent and recurrent eddies and meandering. We offer new insights on the interpretation of cLCS by relating them to the time-mean structure of Eulerian fields such as satellite sea-surface temperature (SST), model sea-surface height (SSH), and eddy, mean, and total kinetic energies (EKE, MKE, and TKE, respectively). Further interpretation of cLCS is based on comparisons with satellite-tracked drifters and synthetic drifter trajectories. The transport patterns associated with persistent Eulerian structures include regions with increased Lagrangian variability and offshore transport. We identify a cross-shelf transport barrier, separating distinct dynamical regimes, and persistent recirculation patterns in the transition region between them. We also show that cLCS highlight the transport patterns that help explain the observed drift of the Chevron's oil spill (November of 2011) and the recent largescale oil slicks observed at Brazilian beaches (from August 2019 to February 2020). Here, cLCS are computed from daily-mean surface velocities from a 13 year (2003-2015) ROMS simulation ${ }^{29,30}$ with an eddy-resolving grid of $1 / 36^{\circ}(\approx 3 \mathrm{~km})$ and 40 vertical levels. Following the method described in Duran et al. ${ }^{26}$, we compute 7 -day sliding window Cauchy-Green Tensors (CGT) in reverse time, from the daily climatological velocity. From these CGT we calculate the monthly and yearly average CGT.

\section{Results}

It is important that the physical interpretation of monthly climatological attraction strength $(c \rho)$ and cLCS are supported by the combined use of complementary data. In this study we use satellite data, in situ observations and numerical model outputs. 


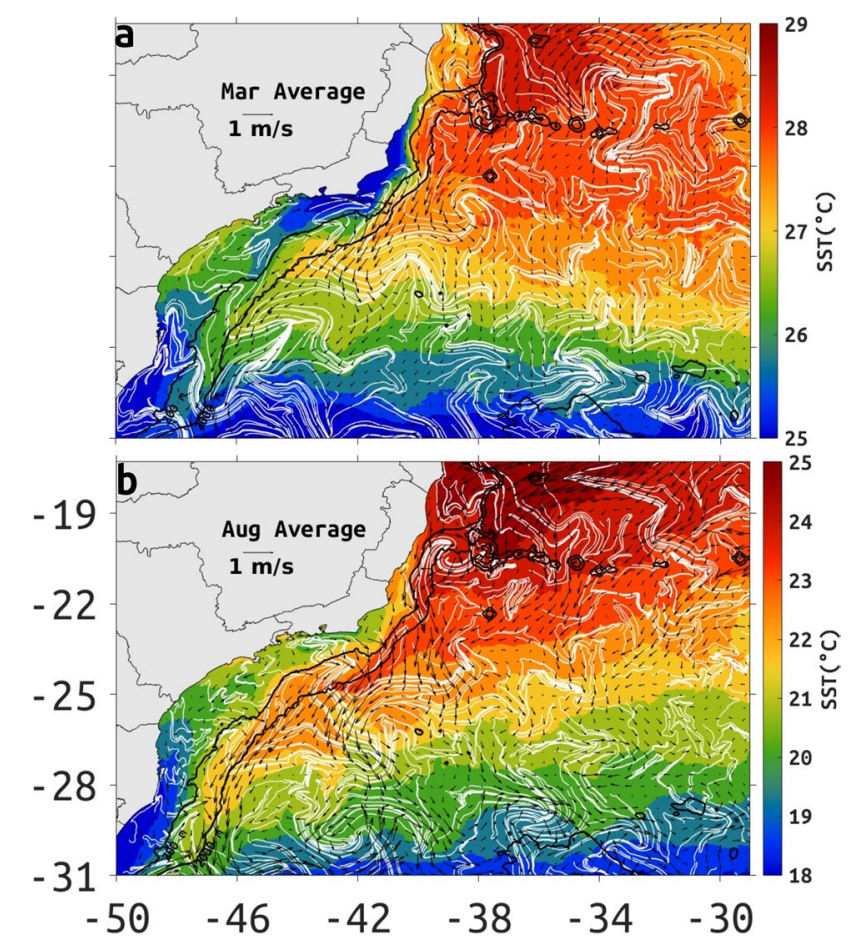

Figure 1. March (a) and August (b) monthly mean SST from the MUR dataset (color shading), with spatial resolution of $0.01^{\circ}$ provided by PODAAC (Physical Oceanography Distributed Active Archive Center), superposed by the corresponding monthly-mean-surface ocean velocity from ROMS (black arrows) and cLCS (white lines). Depth contours of 200- and 2000-m are indicated in black lines. Note that color bars are different for each month. Created with Matlab R2018B (www.mathworks.com).

The mean structure of the BC. The typical mean structure of the BC between 22 and $31 \mathrm{~S}$ is easily extracted by time averaging Eulerian fields. The monthly-mean model Eulerian surface flow aligns well with the advection patterns of monthly-mean satellite SST from multi-scale ultra-high resolution (MUR) dataset, suggesting a continuous surface poleward flow along the 2000-m isobath (Fig. 1).

In the austral summer (Fig. 1a), between 17-20S and 38-29W cLCS suggest Lagrangian transport from east to west, in agreement with the Eulerian mean. Between 20-22S meandering is more common by Vitória-Trindade seamount chain (20S and 39-34W), including over the shelf near 20S where the mean Eulerian flow and cLCS clearly show a meander (March) or an eddy (August). South of about 22S, the BC main axis of the flow is usually oriented poleward along the $2000-\mathrm{m}$ isobath, with climatological squeezelines deforming as chevrons, similar to SST chevrons.

Similar chevrons of climatological squeezelines can also be found in a coastal upwelling region, indicated by low SST near the shore in the austral summer (Fig. 1a), when there is an intensification of upwelling, although coastal circulation inshore of the $200-\mathrm{m}$ isobath is equatorward. In the austral winter the chevron shape is observed only near the upwelling of Cabo Frio (23S and 42W; Fig. 1b).

The advection of TW by the BC causes a zonal front with the cold and low salinity coastal water, between $21 \mathrm{~S}$ and $31 \mathrm{~S}$ in both seasons. We observed the presence of stronger thermal fronts in the austral summer, due the intensification of upwelling at Cabo Frio (23S) and Cabo de Santa Marta (28S). In March, TW between 21 and $30 \mathrm{~S}$ is characterized by surface water with temperatures above $26.5^{\circ} \mathrm{C}$ (Fig. 1a) and in August by temperatures above $21^{\circ} \mathrm{C}$ (Fig. 1b).

Persistent offshore advection can be seen through satellite SST, cLCS and monthly Eulerian velocity in austral summer and winter (Fig. 1a,b). In the winter, the Eulerian mean surface velocity shows persistent offshore flow at $19.5 \mathrm{~S}$ and $39 \mathrm{~W}$, around $23 \mathrm{~S}$ and $39 \mathrm{~W}$, between $25-26.5 \mathrm{~S}$ and $42 \mathrm{~W}$ (Fig.1a). In the summer offshore transport is similarly located but can also be seen around $30 \mathrm{~S}$ and $47 \mathrm{~W}$ (Fig. 1b). Often these Eulerian offshore patterns coincide with cLCS deforming as chevrons, and in the summer they coincide with satellite SST advection. In the austral summer, SST is consistent with offshore advection (e.g. 26S and 42W), and chevron-like cLCS (Fig. 1a), while in the austral winter offshore advection (e.g. $26 \mathrm{~S}$ and $42 \mathrm{~W}$ ) does not coincide with offshore SSH advection, yet cLCS do conform to the offshore Eulerian flow (Fig 1b).

Variability in the $\mathrm{BC}$ is evident in austral summer and winter through an intensification of eddy kinetic energy (EKE), between the 200- and 2000-m isobaths south of about 23S (Fig. 2a,b). This alongshore EKE maxima is collocated to the Eulerian mean peak BC velocity which is closely aligned with the 2000 - $\mathrm{m}$ isobath, the mean peak velocity being in agreement with chevron-shaped cLCS (Fig. 2c,d). The alongshore EKE maxima south of about 22S, between the 200- and 2000-m isobaths, is about $0.1 \mathrm{~m}^{2} / \mathrm{s}^{2}$ and slightly more energetic in the Summer (March). The alongshore MKE maxima is centered along the $2000-\mathrm{m}$ isobath south of about $22 \mathrm{~S}$, it is about 0.1 $\mathrm{m}^{2} / \mathrm{s}^{2}$ in the summer and about $0.05 \mathrm{~m}^{2} / \mathrm{s}^{2}$ in the winter. 

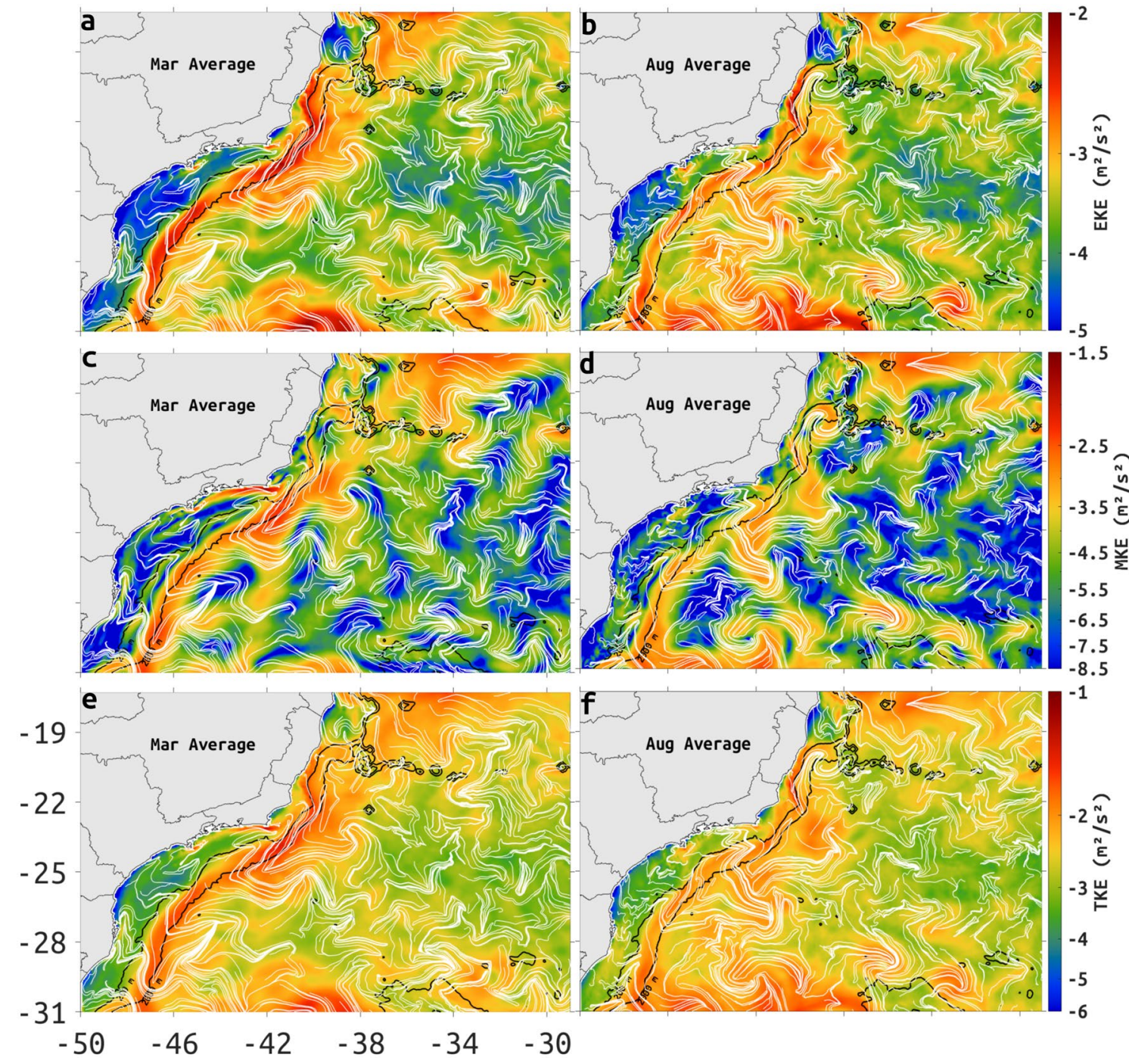

Figure 2. Monthly average maps of EKE (a and b), MKE (c and $\mathbf{d}$ ) and TKE (e and $\mathbf{f}$ ) (color shading) for March (left frames) and August (right frames), from 2003 to 2015 . Units are $\mathrm{m}^{2} / \mathrm{s}^{2}$ in log scale. Monthly cLCS are represented by white lines. The 200- and 2000-m depth contours are represented by black lines. Created with Matlab R2018B (www.mathworks.com).

In the summer, EKE maxima offshore of the 2000-m isobath, are located between 17 and 20S, offshore of the Abrolhos Bank and between 21 and 26S, the latter is adjacent to the alongshore EKE maxima, between the 200- and 2000-m isobaths (Fig. 2a). In the winter, EKE maxima just offshore from the 2000-m isobath can be located between 17-18S, and near 22.5S, 25.5S and 30S (Fig. 2b).

In winter and summer, maxima MKE structures that are just offshore to the mean BC can also be seen, but are more localized near 22.5 and near 25S (Fig. 2c,d). These locations coincide with offshore flow in Eulerianmean velocity (Fig. 1a,b).

The low SST associated with intermittent coastal upwelling off Cabo Frio during austral summer (23S and 41-46W; Fig. 1a) coincides with a coastal jet in the Eulerian-mean velocity which deforms cLCS as chevrons, and can be seen as an MKE maxima (Fig. 2c). In Appendix F of the Supplemental information we show that the results in Figs. 1 and 2 remain qualitatively the same with seasonal averages.

High stretching values ( $c \rho>1$ in logarithmic scale, or $>2.7$ in linear units) are found near steep bathymetry areas such as seamounts (Regions 1, 2, 3 and 5 in Fig. 3a) and upwelling regions (Regions 4, 6, 7, and 9 in Fig. 3a). Medium to high stretching values $(c \rho>0.7$, or $>2$ in linear units) are found adjacent to the BC core between 200- to 2000-m isobaths, and between 23-31S with regions of strong attraction interspersed by weakly-attracting regions (Fig. 3). Along the slope, climatological attraction strength extrema coincides with EKE extrema, including a minimum near region 1 (Figs. 2 and 3 ).

The climatological attraction strength, $c \rho$ shown in Fig. 4, has some variability over the slope (200- to 2000-m isobaths) between $23 \mathrm{~S}$ and $31 \mathrm{~S}$. This variation in $c \rho$ suggests low-frequency variability of Lagrangian transport patterns with a tendency for some cross-slope transport where low $c \rho$ predominates (see Supplementary Figs. S1 and S2). In general, the low frequency time variability suggested by $c \rho$ over the slope, near the latitudes $23.5-24.5 S$ 


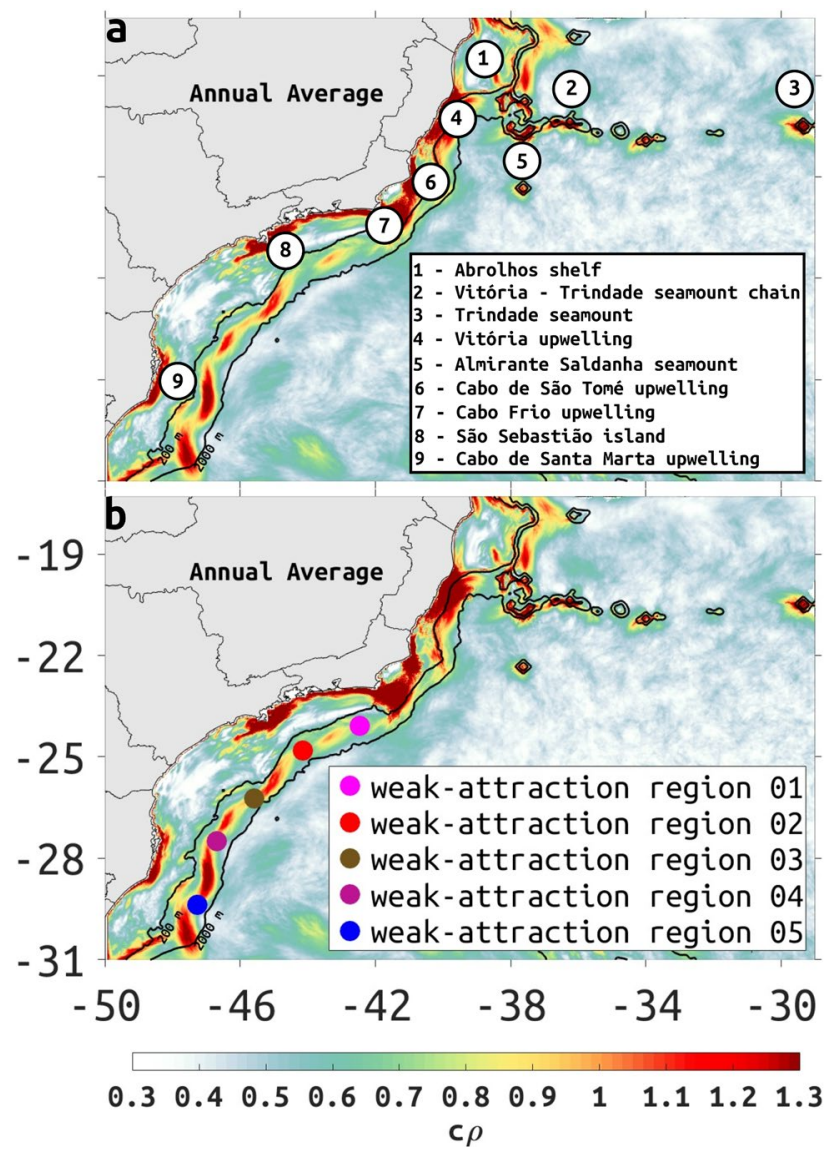

Figure 3. Climatological attraction $c \rho$ (colors, logarithmic scale), computed by yearly averaging 7-day CG tensors from the 2003-2015 climatology, showing (a) locations with high values of annual mean $c \rho(>1,2.7$ in linear units) and (b) regions of weak attraction adjacent to the 2000-m isobath (colored dots).The 200- and 2000-m depth contours are represented by black lines. Created with Matlab R2018B (www.mathworks.com).

and between 26-27S, is largest from December to February. In March, June, July, August and September high values of $c \rho$ can be seen along most of the slope south of 23-25S, in contrast with other months where minima are interspersed with maxima. Continuous high values of $c \rho$ over the slope are observed in April, May, October and November months. The coastline and shallow shelf between 24 and $27 \mathrm{~S}$ has a $c \rho$ minima in all months, sometimes contrasting with a strong maxima along the coastline north of $24 \mathrm{~S}$ (e.g. January through May). The $c \rho$ minima in the nearshore environment and coastline between 24 and $27 \mathrm{~S}$ identifies a stagnant region through the year, a region that should be relatively safe from spills originating outside of the $c \rho$ minima (Supplementary Fig. S3, middle panel). However, any pollution originating within this region including the coastline is unlikely to disperse, thus possibly causing a greater impact due to a higher concentration of contaminants (Supplementary Fig.S3, right panel).

An intensification of $c \rho$ near Cabo Frio upwelling region (Region 7 in Fig. 3a) is observed from January to May due to an increase in speed associated with a coastal jet (Fig. S4) between São Sebastião Island to Cabo Frio (Region 8 to 7 in Fig. 3a). A peculiar $c \rho$ maxima with "U" shape can be seen in the months of April and May when the surface speed bends cyclonically between 23 to $24 \mathrm{~S}$ and 44 and $41.5 \mathrm{~W}$ (Fig. 4, see also Fig. S4).

A description of the mean structure $\mathrm{BC}$ is organized in four different regions based on structures from the model-mean SSH to illustrate upwelling process and persistent mesoscale activity and their association with persistent Lagrangian transport patterns as seen through cLCS (Fig. 5).

The first region (Fig. 5c) comprises a group of zonally oriented topographic features near 20S starting at the Abrolhos shelf on the west (location 1 in Fig. 3a), the Vitória-Trindade Seamount chain (location 2 in Fig. 3a), and the oceanic island complex of Trindade Martin Vaz (location 3 in Fig. 3a) on the east. An important persistent oceanic feature captured by cLCS in this region is the Vitória cyclonic eddy to the south of Abrolhos shelf in addition to the Abrolhos anticyclonic eddy on the east centered around 34.4W (Fig. 5c). The Abrolhos anticyclonic eddy translates from east to west near Vitória-Trindade seamount chain (Region 2 in Fig. 3a) between the latitudes 18 and 20S and longitudes of 38 and 32W (see Fig. S5). The second region (Fig. 5d) is characterized by the presence of coastal upwelling near the Cabo de São Tomé (location 6 in Fig. 3a), identified by low SST values in austral summer (Fig. 1a), just offshore from the upwelling there is a cyclonic structure centered around $22 \mathrm{~S}$ and $40.2 \mathrm{~W}$. Further offshore there is an anticyclonic structure centered at $23 \mathrm{~S}$ and $38 \mathrm{~W}$. Both of these structures 


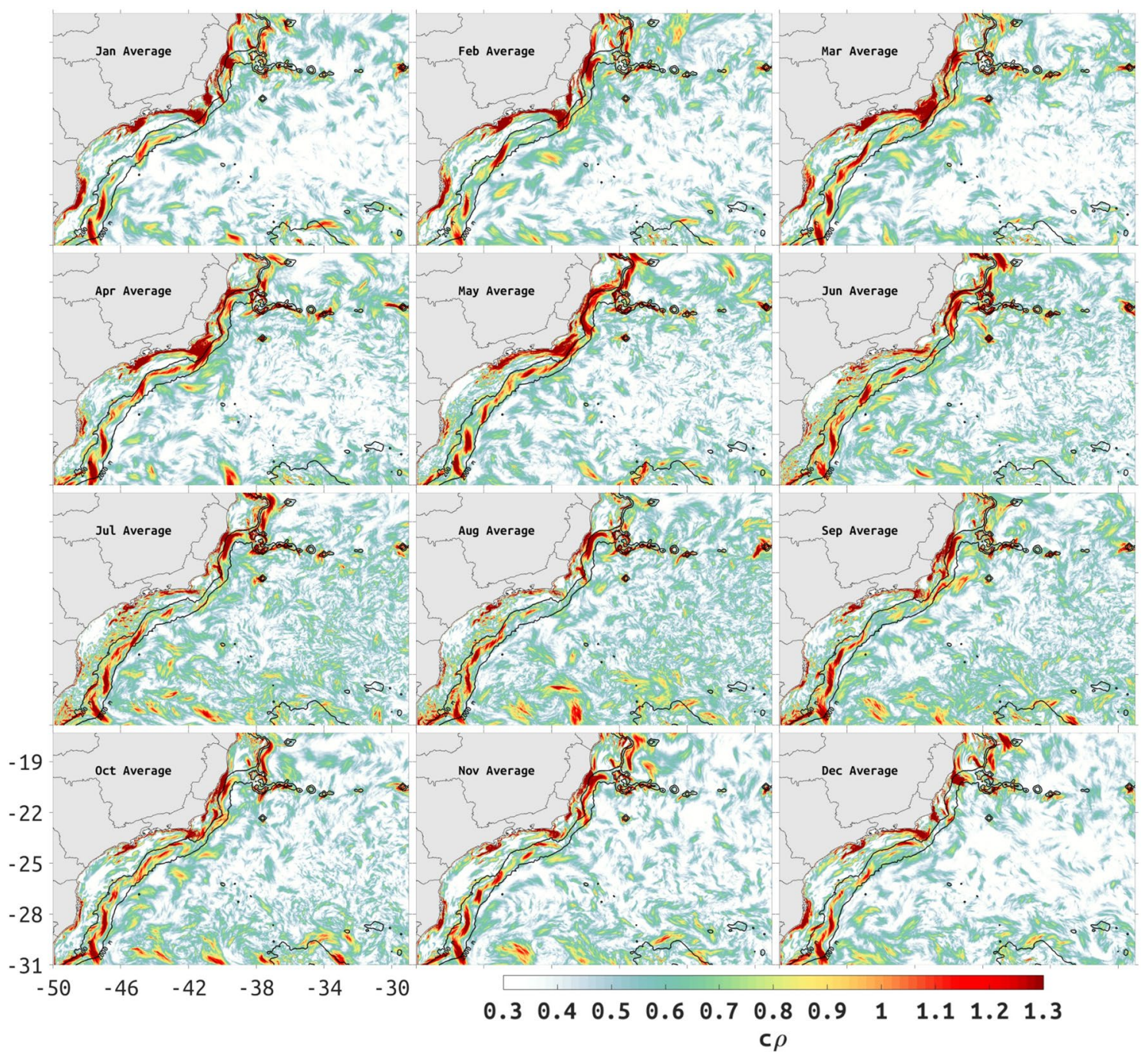

Figure 4. Monthly climatological attraction strength $(c \rho)$ in the SWA. Note the discontinuous meridional distribution of high (red) $c \rho$ values between the 200- and 2000-m depth contour lines (thin black lines). Created with Matlab R2018B (www.mathworks.com).

induce persistent Lagrangian transport seen through the deformation of cLCS. This region also coincides with EKE and MKE maxima (Fig. 2) protruding offshore from the 2000-m isobath, and with an Eulerian mean velocity (Fig. 5d) all of which suggest offshore transport. A synthetic drifter experiment confirms that the persistent mesoscale structures are likely to cause considerable cross-shelf transport (see Supplementary Fig. S2a,b). A third region (Fig. 5e) is located in front of the east-west oriented coast of Rio de Janeiro (location 7 in Fig. 3a) with a coastal upwelling jet near Cabo Frio deforming cLCS. A couple of cyclonic and anticyclonic features between 23-25S, and the 200- and 2000-m isobaths cause an onshore-offshore-onshore-offshore sequence, although cross-shelf transport seems limited not passing the $2000-\mathrm{m}$ isobath where the core of the BC can be seen except possibly near $23 \mathrm{~S}$. Further offshore near $41 \mathrm{~W}$ and $25 \mathrm{~S}$, there is a SSH maxima associated with recurrent anticyclonic Lagrangian flow depicted by cLCS deformation (Fig. 5e, see also Fig. S5). Near Cabo de Santa Marta (location 9 in Fig. 3a) is the fourth and southernmost region (Fig. 5f), where the surface flow is influenced by a distinctive coastal upwelling region in $29 \mathrm{~S}$, and the presence of two dipole-like structures, suggesting cross-shelf variations over the 200-m isobath, restricted inshore of the 2000-m isobath. In Appendix F of the Supplemental Information we show seasonal averages of SSH.

The BC axis (see MKE in Fig. 2c,d, and SST and cLCS chevrons in Fig. 1) is positioned between anticyclonic and cyclonic structures (Fig. 5e). As it flows from northeast to southwest, the eastern flank of the BC gains counterclockwise rotation offshore of the $2000-\mathrm{m}$ isobath. The alongshore flow in the east-west oriented shelf near region 7 (Fig. 3), becomes offshore flow from Cabo Frio as it approaches the 200-m isobath, and is fed by a clockwise circulation over the 200-m isobath, connecting with the counterclockwise circulation offshore. Thus, the monthly-mean Eulerian velocity suggests limited cross-shelf transport between the 200- and 2000-m isobaths (Fig. 5e), that coincides with weak attraction $c \rho$ (Figs. $3 \mathrm{~b}$ and 5), and coincides also with the Eulerian-mean anticyclonic and cyclonic structures (b and $c$ in the Fig. 6) found on both sides of the BC axis.

Based on this, we propose a schematic representation of the persistent meandering between 23 and $27 \mathrm{~S}$ (Fig. 6). The strength of normal attraction along the cLCS deformed as chevrons by the BC is indicative of the 

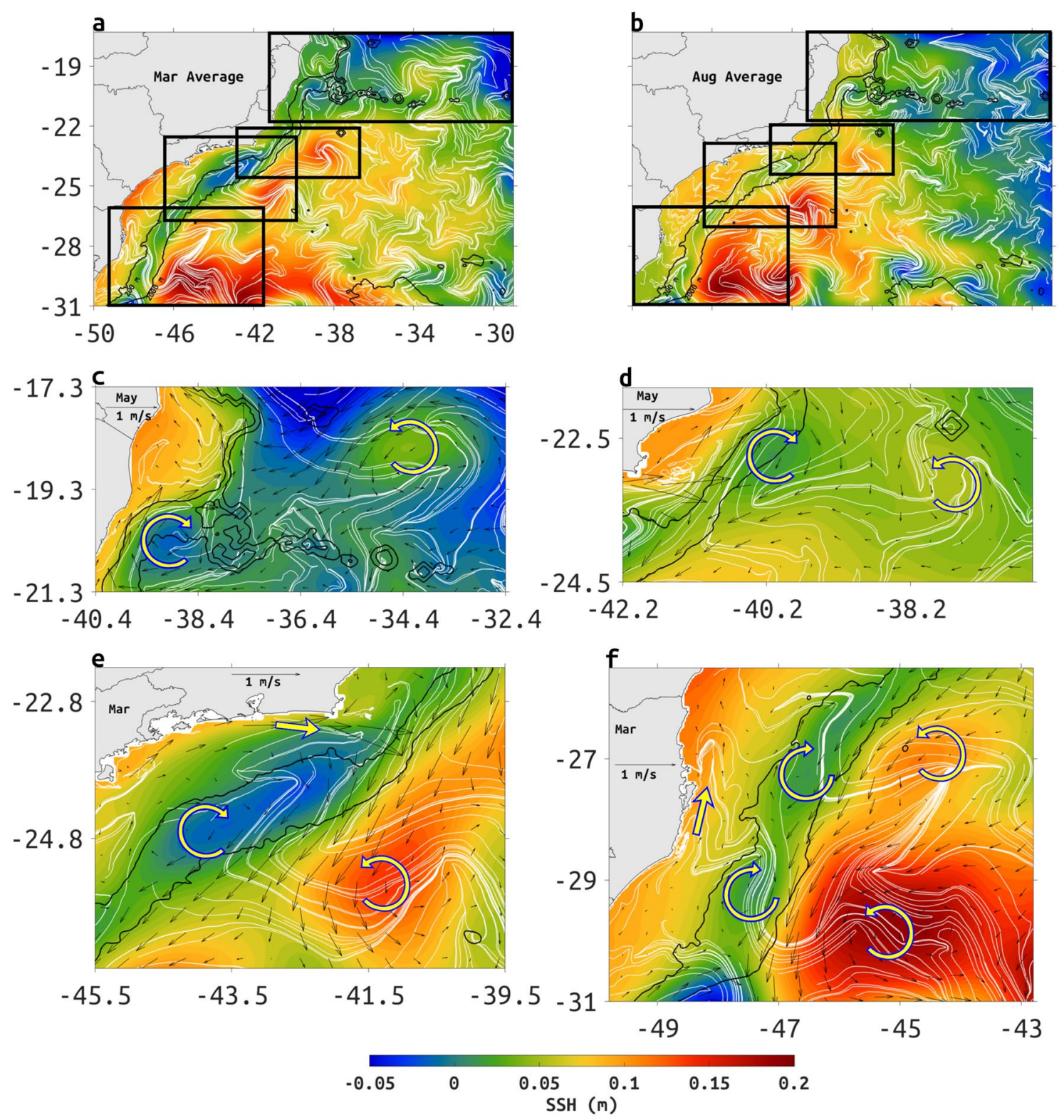

Figure 5. March (a) and August (b) monthly climatological squeezelines (white lines) over model monthlymean SSH. Black rectangles indicate regions shown in panels (c)-(f). (c) Abrolhos Bank region (location 1 in Fig. 3a), (d) Cabo de São Tomé (location 6 in Fig. 3a), (e) Cabo Frio (location 7 in Fig. 3a) and (f) Cabo de Santa Marta (Region 9 in Fig. 3a). The presence of cyclonic and anticyclonic eddies features are highlighted by curved arrows. Straight arrows indicate the direction of coastal jets at upwelling regions. Reference months are indicated at the top left of each map. The vector scale is on the top of each map. Depth contours of 200- and 2000-m are represented by thin black lines. Created with Matlab R2018B (www.mathworks.com).

kinematics: along the BC core between 25-26S, cLCS are weak ( $c \rho \sim 0.3$ in logarithmic scale) indicating the core of the BC, where normal attraction is weak. Between 24-25S however, the BC core has higher values of $c \rho(\sim 0.6$ in logarithmic scale) reflecting an increase in normal attraction that is associated with the cross-shelf circulation described above. Between 23-24S, cLCS reach high $c \rho$ values ( $>0.8$ in logarithmic scale) reflecting the coastal tributary to the alongslope flow, that is related to the coastal upwelling jet off Cabo Frio (see a in the Fig. 6). There are similar dipoles adjacent to the BC at different latitudes (Fig. 5d-f), and the cLCS (Fig. S5) and c $\rho$ show a similar response (Fig. S4).

Variability of surface flow assessed through drifters. From a total of 352 trajectories of satellitetracked $15 \mathrm{~m}$ drogued drifters (SVP, Surface Velocity Project ${ }^{31}$ ), distributed by NOAA's Global Drifter Program (GDP), and iSPHERE, distributed by Prooceano, with consent of PetroRio, interpolated to 6-h intervals, a minority crossed at some time the $2000-\mathrm{m}$ isobath and less than $30 \%$ of drifters cross the $200-\mathrm{m}$ isobath (Table 1). Some of these trajectories are plotted with the annual $c \rho$ maps (Fig. 7) to highlight the quasi-steady 


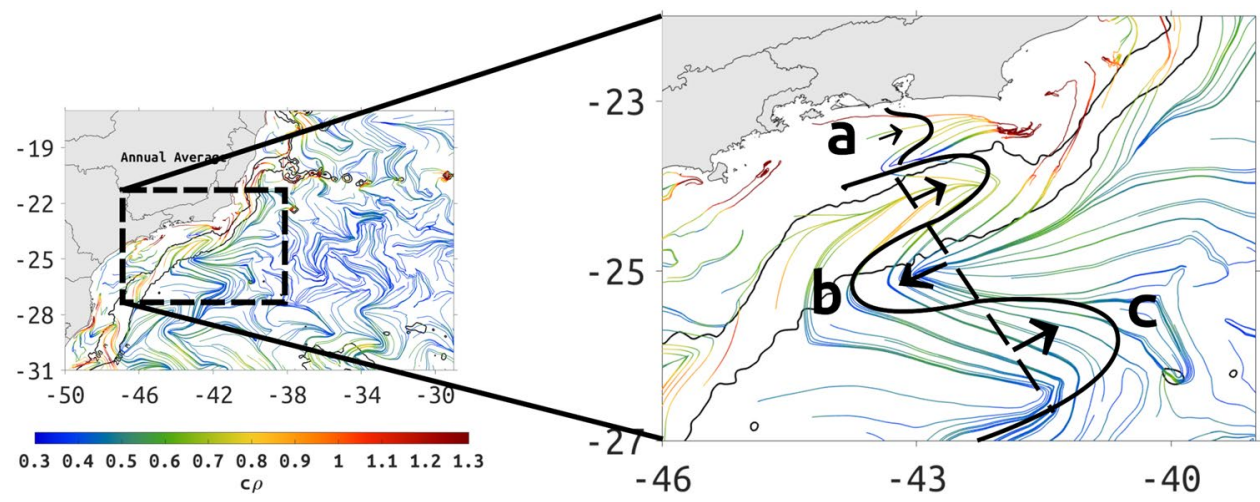

Figure 6. Schematic representation of persistent Lagrangian transport based on the annual averaged cLCS, colored according to annual $c \rho$. The map to the left shows the full domain of the study and the map to the right is a zoom in to the dashed rectangle. The 200- and 2000-m depth contours are represented by thin black lines. Created with Matlab R2018B (www.mathworks.com).

\begin{tabular}{|l|l|}
\hline Regions & Drifters (\%) \\
\hline Weak attraction region 01 & 10.51 \\
\hline Weak attraction region 02 & 29.54 \\
\hline Weak attraction region 03 & 16.47 \\
\hline Weak attraction region 04 & 10.51 \\
\hline Weak attraction region 05 & 17.04 \\
\hline
\end{tabular}

Table 1. Percentage of satellite-tracked drifters with $15 \mathrm{~m}$ drogues (SVP) distributed by NOAA'S GDP, with trajectories interpolated in $6 \mathrm{~h}$ intervals, that crossed the $2000-\mathrm{m}$ isobath along a region of weak attraction, as indicated in Fig. 3b. The same drifter can be counted more than once if it crossed more than one region of weak attraction. ${ }^{*}$ The percentage is related to the total of 352 drifters.

Lagrangian transport patterns associated with the BC around 2000-m isobath. The observed transport patterns show a region where a number of drifters spend several days trapped in eddies and meanders near the VitóriaTrindade Seamount Chain (Fig. 7a, see also Region 2 in Fig. 3a) and Almirante Saldanha seamount (Region 5 in Fig. 3a). Drifters may also spend some time confined in weakly attracting regions, represented by low $c \rho$ values or confined inshore of the $200-\mathrm{m}$ isobath which also has low $c \rho$ values, except at some locations near the coastline (Fig. 7b).

When drifters travel just inshore of the BC core, between the 200- and 2000-m isobaths, there is some meandering (Fig. 7c); drifters that move offshore of the 2000-m isobath do so where there are persistent cyclonic structures (Fig. 5e,f). Further examples of cross-shore transport show that the persistent cyclonic structures between 23-25S, 26.5S and 29S (Fig. 5e,f) tend to influence where drifters will move onshore or offshore (Fig. 7c-f). Onshore transport is less likely to cross the 200-m isobath than the 2000-m isobath. The cross-shelf flow of drifters between $24 \mathrm{~S}$ and $27 \mathrm{~S}$ (Fig. $7 \mathrm{c}-\mathrm{e}$ ) is more likely over regions of low $c \rho$ than over regions of high $c \rho$.

The effect of persistent meandering and eddy-like structures (Fig. 5a,b) on satellite-tracked drifters can clearly be seen as high values of Probability Density Estimates (PDE, see Methods section) measuring the likelihood of drifters visiting a region. In February and May, regions of high PDE tend to be confined within $c \rho$ maxima that occur close to upwelling regions and along steep bathymetric features (Fig. 3, regions 2 and 5).

Between 24-30S, PDE values tend to be well aligned with the slope, with values diminishing considerably towards the coast at any given latitude. Exceptions are localized near 25S in February, May and August, when medium values of PDE $\left(\approx 6-10 \times 10^{-3}\right)$ can be seen just inshore of the $200-\mathrm{m}$ isobath. PDE maxima $\left(>11 \times 10^{-3}\right)$ are confined offshore of, and adjacent to the $2000-\mathrm{m}$ isobath. All drifters can be seen in the Supplemental Information (Fig. S6). The drifter PDE suggests seasonal variability with PDE maxima $\left(>11 \times 10^{-3}\right)$ located only north of $24 \mathrm{~S}$ in the summer and autumn (Fig. 8a,b), with winter being a transition as PDE maxima diminish north of $24 \mathrm{~S}$ and increase south of $26 \mathrm{~S}$ (Fig. 8c), and in spring PDE maxima $\left(>11 \times 10^{-3}\right.$ ) is limited to south of $26 \mathrm{~S}$.

In all cases PDE maxima tends to be just offshore of the 2000-m isobath, the only exception being a maximum centered near $22 \mathrm{~S}$ and $34 \mathrm{~W}$, mainly found in summer, autumn and winter.

The isolated region next to the coastline between 24 and $27 \mathrm{~S}$ has a larger zero PDE region in autumn and winter when $c \rho$ is also negligible in this region (Fig. 8b,c) relative to $c \rho$ in summer and spring (Fig. 8a,d). In all seasons this coastal region is well isolated. Another region that tends to be isolated is the coastline north of $20 \mathrm{~S}$, especially in autumn, winter and spring (Fig. 8b-d). 


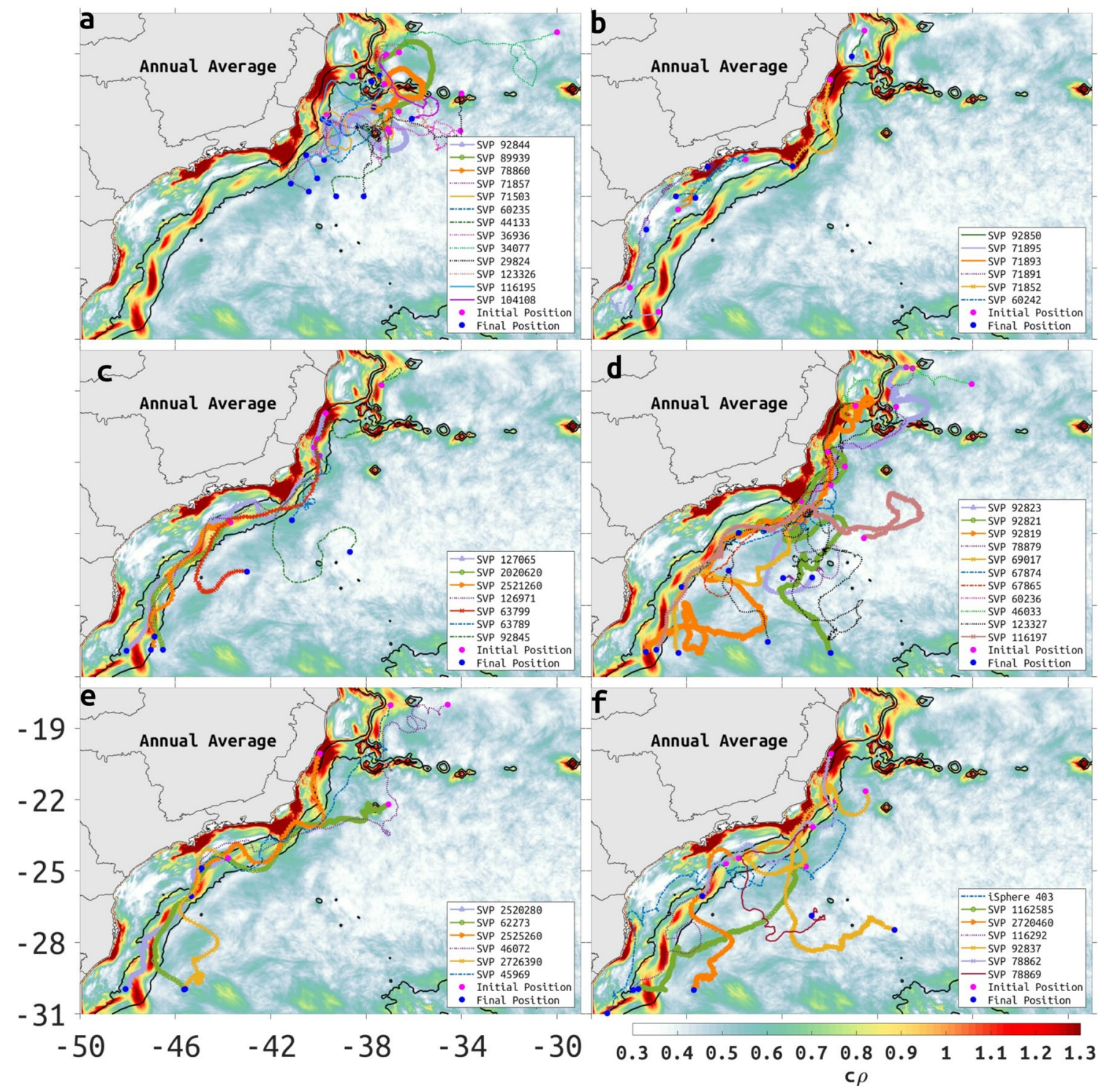

Figure 7. Selected trajectories of satellite-tracked SVP drifters, interpolated at $6 \mathrm{~h}$ intervals, distributed by NOAA'S Global Drifter Program, and of iSPHERE, distributed by Prooceano with consent of PetroRio, superposed to the annual-mean $c \rho$. (a) Drifters trapped in eddies and meanders near the Vitória-Trindade Seamount Chain and Almirante Saldanha seamount; (b) drifters confined in weakly attracting regions or inshore of the 200-m isobath; (c) drifters traveled inshore of the BC core, between the 200- and 2000-m isobaths; (d) drifters moved offshore of the 2000-m isobath; (e) drifters with onshore-offshore oscillatory motion; (f) drifters with a large onshore-offshore displacement. Depth contours of 200- and 2000-m are represented by thin black lines. The identification number of each Surface Velocity Drifter is shown in the insert of each frame. Created with Matlab R2018B (www.mathworks.com).

Oil spill at Frade's field. The cLCS and $c \rho$ computations have been successfully used to estimate the likely trajectory of oil spills such as during the accidents in the Gulf of Mexico in 1979 and in $2010^{26}$.

We show that performing the same computations using a free-run eddy-resolving ocean model it is possible to achieve a good level of agreement between CLCS and the behavior of a much smaller offshore oil spill that occurred at the Frade's Field (Fig. 9a), located $120 \mathrm{~km}$ off the coast of Rio de Janeiro State (Brazil), on November 7, 2011. The spill reached $1998 \mathrm{~km}^{2}$ in less than 15 days, being contained on December 30 of the same year (Fig. 9b).

The agreement with cLCS can be qualitatively assessed by comparing the oil spill trajectory with the trajectories of 30 synthetic drifters released in the same month of the accident and with six satellite-tracked iSphere drifters deployed between November and December, 2011 (Fig. 9c). The synthetic drifters were allowed to move for 60 days, which is the same period the real spill progressed before its final containment.

Part of the synthetic drifters (purple trajectories to northwest in Fig. 9c) agree with the observed spill trajectory (red shape) and with one of the iSphere drifters deployed in November (magenta trajectory-iSphere 403-in Fig. 9c), for the most part moving along a cLCS. The other part of the synthetic drifters (purple trajectories to 


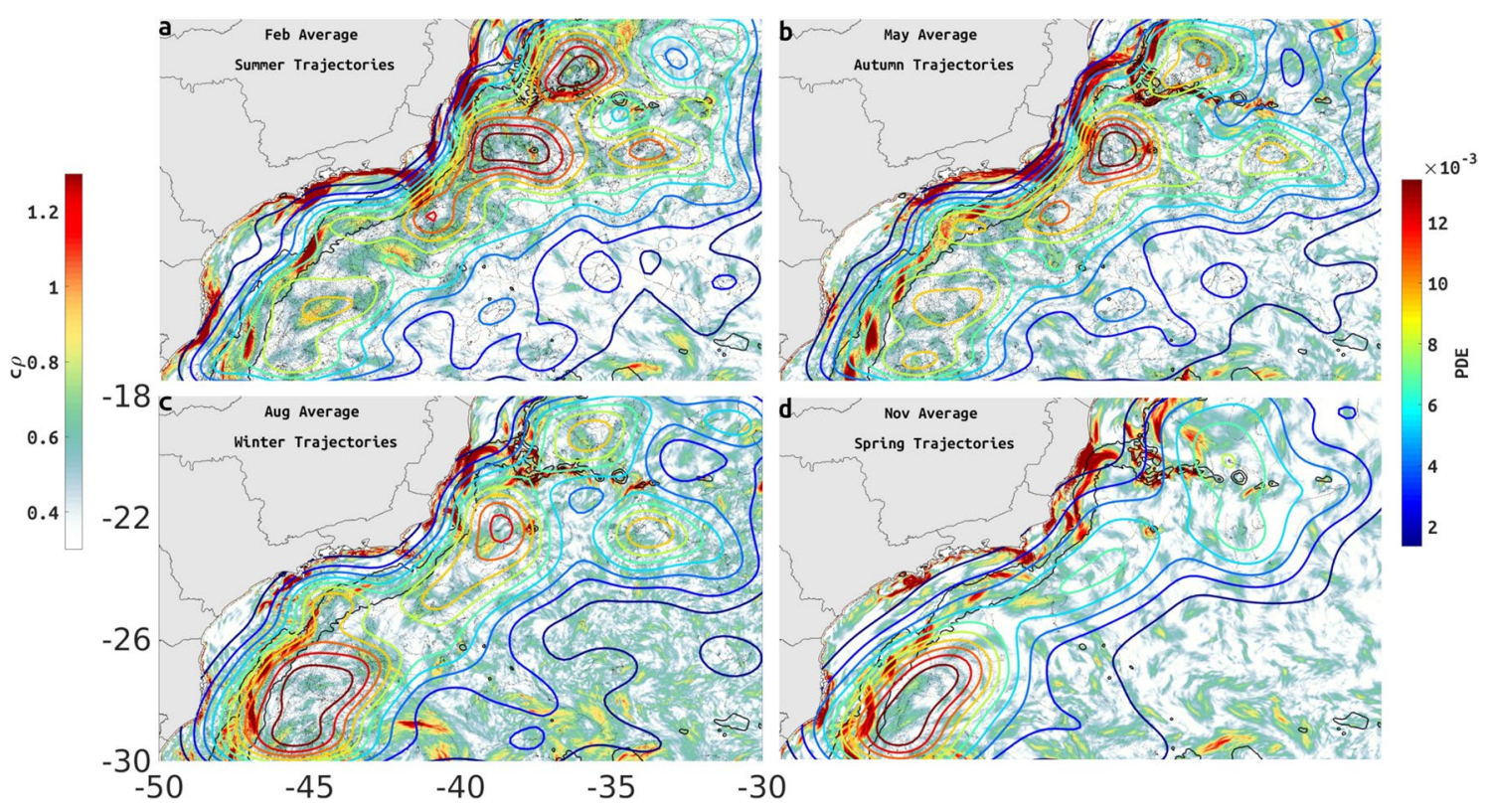

Figure 8. The PDE (coloured contours) of (a) all austral Summer trajectories (Jan-Feb-Mar) over the $c \rho$ distribution for February (color shading), (b) all austral Autumn trajectories (Apr-May-Jun) over the $c \rho$ values for May (color shading), (c) all austral Winter trajectories (Jul-Aug-Sep) over the $c \rho$ values for August, and (d) all austral Spring trajectories (Oct-Nov-Dec) over the $c \rho$ distribution for November. Depth contours of 200and 2000-m are represented by black lines. Created with Matlab R2018B (www.mathworks.com).

southwest in Fig. 9c) correspond with iSphere trajectories (orange, blue, yellow, gray and cyan lines in Fig. 9c) deployed in December, and the only other CLCS originating where the oil spill originated and where synthetic and real drifters were released. Thus, synthetic drifters, iSphere trajectories and CLCS are all in good visual agreement: there are two main transport patterns originating at the spill location. While the oil spread along one of the cLCS (Fig. 9b), it did not follow the monthly mean surface currents for November (Fig. 9d). Indeed the mean Eulerian velocity is often perpendicular to CLCS originating at the location of the spill.

Notice that CLCS are accurate indicators of the first part of the drifter trajectories-they were designed to extract likely transport patterns over periods of about one week. The oil spill started in November near an upwelling region (Region 6 in Fig. 3b, see also Fig. 9d) and permeated the southeast near the mean position of a cyclonic feature (Fig. 9e,f, see also 5d). The oil spill final positions coincide with the persistent squeezelines deforming into chevrons in November (23S and 39W) and advecting the oil spill away from the 2000-m isobath. We note how the cLCS agree with the thermal fronts (Fig. 9d), as with the low-frequency SSH (Fig. 9e) and EKE (Fig. 9f) distribution.

A large-scale oil contamination in Northeast Brazil with unknown origin. In 2019, Brazil experienced an oil-related environmental emergency that impacted a large number of beaches as far south as the state of Rio de Janeiro, reaching an extension of almost $4000 \mathrm{~km}^{32,33}$.

Since late August, when it was first detected, more than a thousand beaches have reported occurrences of oil patches, including 12 marine protected areas ${ }^{32}$. By November, over 2000 metric tons of oil were removed from these beaches ${ }^{34}$ and there is still no indication or evidence of its origin ${ }^{32}$, since crude oil may drift as shallow subsurface patches, making it difficult to use satellite sensors for monitoring.

One of the most important Marine Protected Areas, the Abrolhos Bank, was oiled in early November 2019. This area is internationally recognized as a marine biodiversity heritage $\mathrm{e}^{35-38}$ and has been included in the 16th round of bidding for exploration and production of oil and natural gas, under the concession regime, opened in December 2018 (Resolution CNPE no. 17/2018 and CNPE no. 03/2019 ${ }^{39}$ ).

We show the location of known oiled beaches within our study area as per November of 2019 (Fig. 10a-d), December of 2019 (Fig. 10e-h), January of 2020 (Fig. 10i,j), and February of 2020 (Fig. 10k,l) (IBAMA, 2020). In this area, the oil beached for the first time during the months of November (Fig. 10a-c) and December (Fig. 10g). The floating oil moved from north to south following the BC and, although most of the contaminated coastline is outside our model domain, it is possible to note that regions of maximum values of $c \rho(>1.3,3.7$ in linear units) are strong indicators of oil beaching, both for a single time (Fig. 10a,c,e,g) and for a repeated occurrence (Fig. 10b,d,f,h-l).

\section{Discussion}

We offer, for the first time, an integrated representation for the role of eddies and meanders in shaping the mean flow of the $\mathrm{BC}$ based on the calculation of cLCS. The quasi-steady nature of these Lagrangian structures allows the identification of the pervasive and consistent influence of mesoscale features in this western boundary current. 

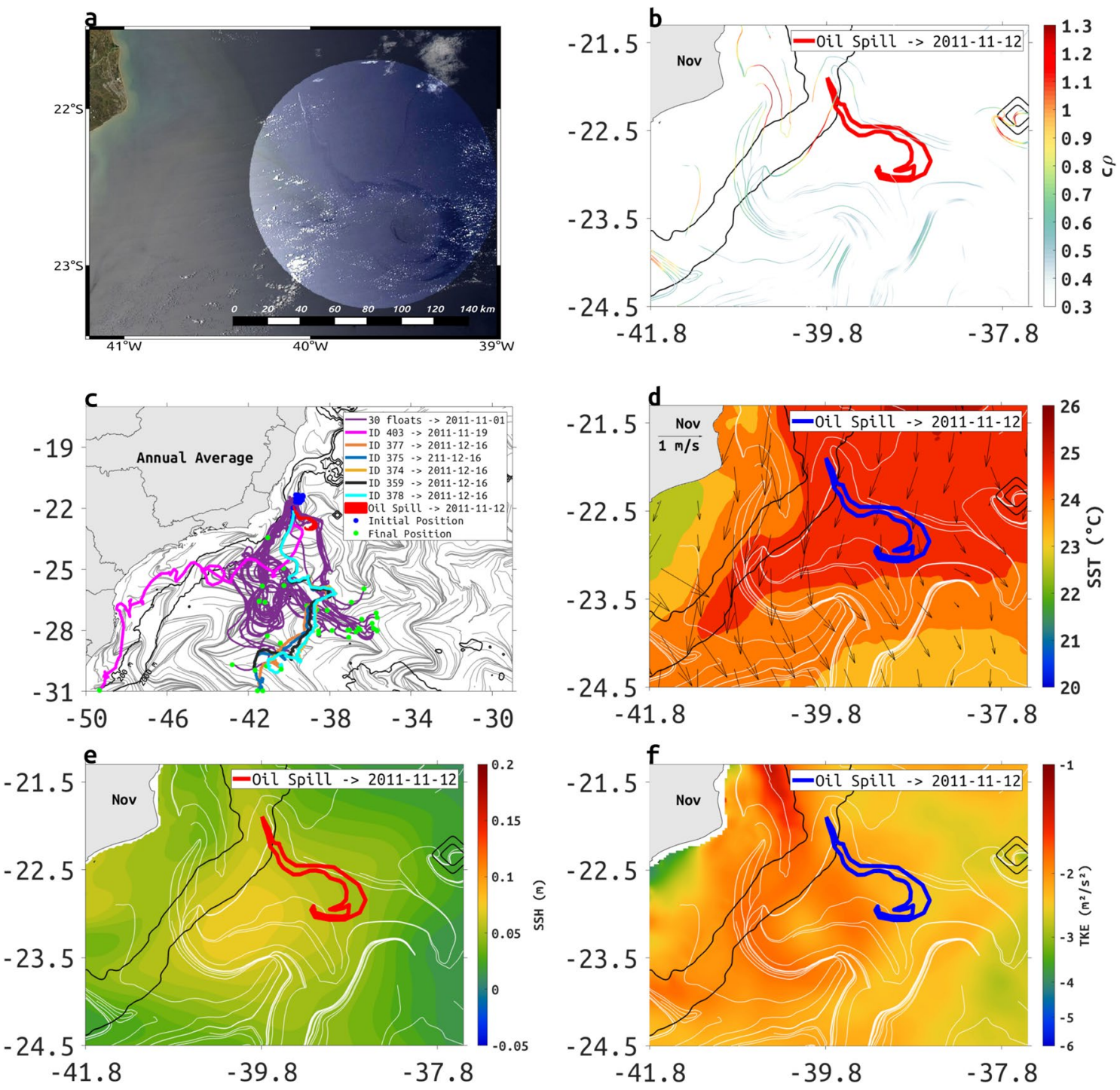

Figure 9. (a) The Chevron oil spill as observed by a true-color MODIS satellite image composite (courtesy of Petrobras) from 12th November, 2011 at 10:30 (UTC-3) in the Frade's field. (b) The shape of Chevron's oil spill (red polygon) over the cLCS for November coloured according to their strength of attraction $c \rho$. (c) The chevron's oil spill (red filled polygon), the 60 day trajectories of 30 ROMS synthetic-drifters launched in November 1st, 2011 (purple lines), and the trajectories of 06 iSphere drifters (courtesy of Prooceano and PetroRio S.A.) launched between November and December of 2011 (magenta, orange, blue, yellow, gray and cyan lines) plotted over the annual climatological squeezelines (grey contours). The dates of deployment and ID of each iSphere are identified in the figure insert. (d) Chevron oil spill (blue polygon) over the ROMS surface velocity (black arrows), MUR SST (color shading), and cLCS (white lines), all averaged for November. (e) Chevron's oil spill (red polygon) over the mean ROMS SSH (color shading) and cLCS (white lines) for November. (f) Chevron's oil spill (blue polygon) over the ROMS TKE (color shading, in log scale) and the November cLCS (white lines). Depth contours of 200- and 2000-m are represented by thin black lines. Created with Matlab R2018B (www.mathworks.com).

Climatological squeezelines deforming into chevron shapes can be seen along the axis of the mean BC coinciding well with chevron shapes from satellite SST, as it is advected by the mean flow. These structures characterize the $\mathrm{BC}$ core at the surface positioned along the $2000-\mathrm{m}$ isobath, with a good seasonal agreement between model and high resolution satellite data (Fig. 1).

High resolution model output indicates that CLCS deformation also responds to zonally persistent cross-shelf SSH transition from positive (high) values near coastline to low (negative) values between 200- and 2000-m and back to positive (high) offshore from the $2000-\mathrm{m}$ isobath (Fig. 5a,b). Zonally-paired cyclonic and anticyclonic structures are embedded in this transition, also causing the cLCS to deform into chevrons. In a recent work, Beron-Vera et al. ${ }^{40}$ found similar chevrons straddling the Malvinas Current lagrangian axis, and showed it was a persistent structure by superimposing shearless-parabolic LCSs that behaves as a cross-shelf transport barrier. 


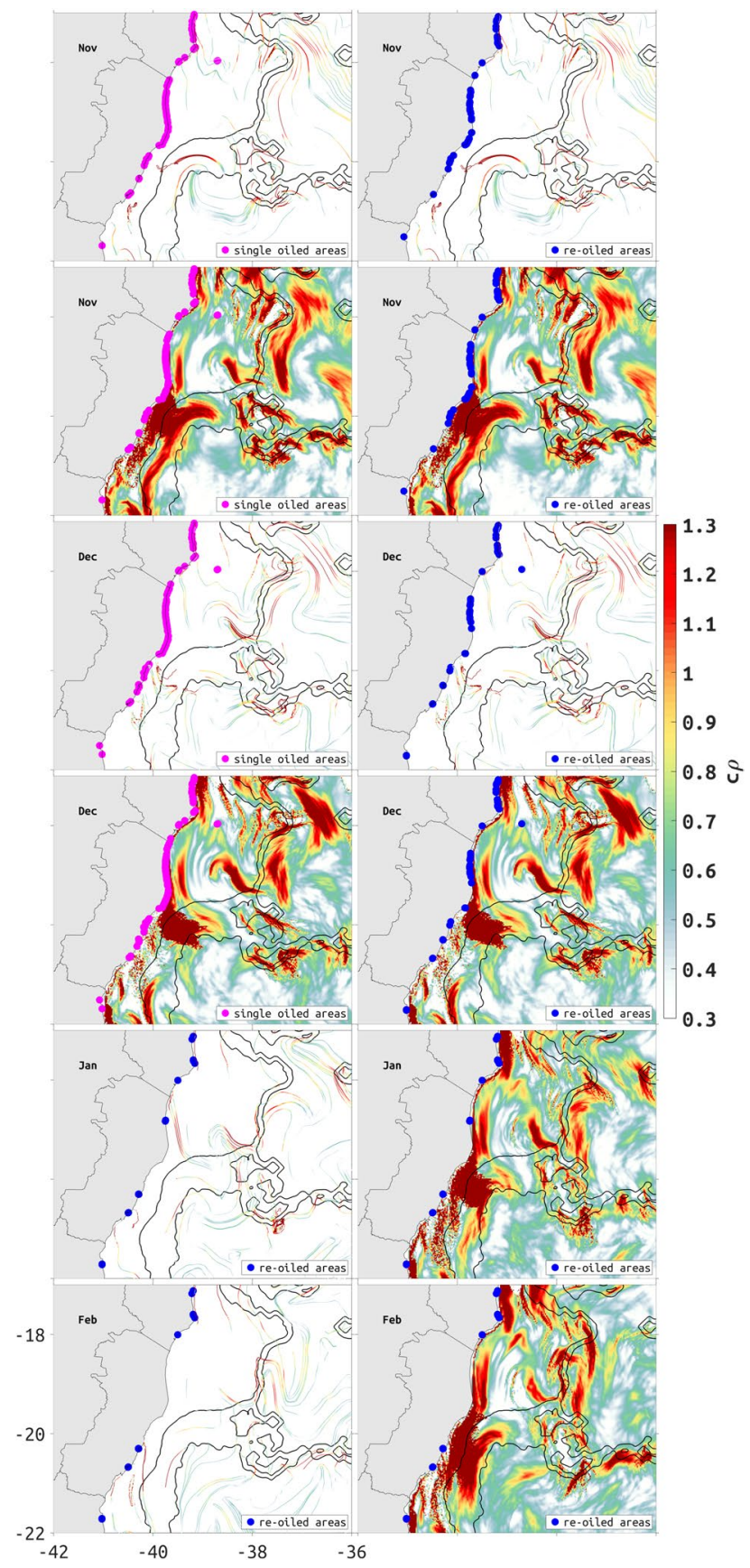

Figure 10. Location of beaches along the Brazilian coast within the study area that were oiled for the first time (pink dots) and that were re-oiled (blue dots) in November (a-d) and December (e-h) of 2019, and January $(\mathbf{i}-\mathbf{j})$ and February (k-1) of 2020. Depth contours of 200- and 2000-m are represented by thin black lines. Oiled sites are superposed to monthly mean cLCS (colored lines) and $c \rho$ (color shading) to indicate transport patterns and particle attraction sites. Created with Matlab R2018B (www.mathworks.com).

Indeed, we show that hyperbolic cLCS can also identify the deformation of fluid as chevrons along the core of the BC, in close visual agreement with monthly-mean satellite SST chevron-like advection patterns (Fig. 1).

A number of independent studies have discussed the presence of mesoscale features along the BC ${ }^{13,24,41-44}$, frequently invoking the interaction with sharp topographic gradients and surface-subsurface flow shear as inducing the formation of cyclonic and anticyclonic meanders with consequent pinching off of eddies ${ }^{45,46}$. During the summer, the cLCS deformation represented by the chevrons covers a large area with seamounts and sharp change in coastline orientation, coincident with EKE maxima $\left(-2 \mathrm{~m}^{2} / \mathrm{s}^{2}\right.$, in logarithmic scale, $0.13 \mathrm{~m}^{2} / \mathrm{s}^{2}$ in linear units) extending offshore of the Abrolhos Bank and between 21S and 26S (Fig. 2a). During the winter, EKE maxima is less organized (Fig. 2b), possibly as a result of the increase in the number of northward-moving cold atmospheric fronts. The presence of persistent meanders and eddies along the $\mathrm{BC}$ axis is also evident in the 
seasonal (monthly means for March and August) EKE and MKE maps (Fig. 2a-d), monthly-model SSH (Fig. 5), seasonal PDE of drifter trajectories (Fig. 8) and model monthly mean surface velocities (Fig. S5). The orientation and location of cLCS tend to follow these known features, with our model SSH indicating both cyclonic (Vitória Eddy, Fig. 5c) and anticyclonic rotation (Abrolhos Eddy, Fig. 5c), near the Abrolhos region and Vitória-Trindade chain respectively (locations 1, 4, and 2 in Fig. 3a). Intense flow shear caused by the Abrolhos Bank eastward shelf projection and the Vitória-Trindade seamount chain are both evident as high $c \rho$ values $(>1,2.7$ in linear units, see Fig. 4) and chaotic trajectories of drogued drifters (Fig. 7a).

As the BC moves southwards, it crosses a wind-induced upwelling region around $21 S^{47,48}$ in the Cabo de São Tomé Region (location 6 in Fig. 3a, see also Fig. 5d and S8a), characterized by persistent year-round high $c \rho$ (Fig. 4). The cLCS deformation in the São Tomé eddies depicted in Fig. 5d has a similar shape to those found along the $\mathrm{BC}$ axis further south, but with the offshore eddy displaying a cusp bent towards the direction of anticyclonic rotation. As these chevrons are formed distant from the BC axis, their shapes tend to conform to the eddy rotation. The onshore eddy is a semi permanent cyclonic feature (see Fig. S8a-c) originated from the detachment of a BC unstable meander likely induced by baroclinic instability ${ }^{23,49,50}$. The persistent meanders and the cyclonic eddies they generate are known to induce or enhance coastal upwelling ${ }^{51}$, here we associate the upwelling with high attraction values $(>1,2.7$ in linear units) of $c \rho$ (Fig. 4). There is a Lagrangian confluence region just south of the upwelling of Cabo Frio (location 7 in Fig. 3a) associated with the presence of cyclonicanticyclonic features on both sides of the 2000-m isobath near 25S (Fig. 5e, Fig. S8a-c). Here, our computations of $c \rho$ and cLCS accurately captured the main elements of surface circulation known as a current-eddy-upwelling region $^{51}$, offering a spatio-temporally Lagrangian integrated view of a dynamically complex system. The persistence of Lagrangian patterns found in this study is consistent with the regional dominance of low-frequency variability, e.g. as reported by Ponsoni ${ }^{19}$. Vertical contributions to the Lagrangian transport patterns described in this paper can be quantified by computing the change in the horizontal surface area along the trajectories used to compute cLCS- the method is described in Appendix A of Duran et al. ${ }^{26}$, and consists of computing the fractional change of area as the Jacobian determinant of each flow map used to compute cLCS. The result here, as in Duran et $\mathrm{al}^{2}{ }^{26}$, is that attraction is due to divergence-free confluence: The mean along-path change of area in this study is order $0.01 \%$, with a standard deviation that is always less than $1 \%$. Such weak vertical motion is consistent with the dominance of low-frequency variability. Figures of the fractional change of area can be found in Fig. S13 and monthly Eulerian divergence in Fig. S12.

Further south, Cabo de Santa Marta (location 9 in Fig. 3a) is dynamically similar to Cabo Frio with alternating anticyclonic (offshore) and cyclonic (inshore) flows (Fig. 5f) that coincide with satellite SST advection (see Fig. S8d) enhanced by baroclinic instability ${ }^{13}$. The persistent shelf-break upwelling results from the interaction of the $\mathrm{BC}$ with coastline orientation and shelf topography ${ }^{52}$. During the summer, wind forcing enhances upwelling and in the winter a northward flow advects cold, low-salinity water from the Plata river ${ }^{53}$ (Fig. 1a). The zonally organized cLCS around Cabo de Santa Marta have chevrons structures over the MKE maxima (Fig. 2c,d) along the axis of the mean BC flow.

The cLCS extracted quasi-steady Lagrangian transport patterns associated with persistent meanders and rotational structures, as indicated in different regions (Fig. $5 \mathrm{c}-\mathrm{f}$ ). When the BC axis is over the 2000-m isobath, south of about $22 \mathrm{~S}$, frontal meanders develop as a response to baroclinic instability due to vertical shear associated with the $\mathrm{BC}$ and the Intermediate Western Boundary Current flowing below 500-m depth ${ }^{13}$. As these meanders grow they can cause a reversion in the surface flow in the inshore front of the $\mathrm{BC}$. We have used the annual averaged cLCS to propose an schematic representation, shown in Fig. 6, of the quasi-stationary persistent meander flow based on the example of Fig. 5e. A similar baroclinic flow was obtained by Calado et al. ${ }^{51}$ in an ocean model experiment with an horizontal resolution of $13 \mathrm{~km}$ and $20 \sigma$ levels showing the existence of a quasistanding vorticity wave pattern in the region. The typical cyclonic meandering between 200- and 2000-m deep is also known to induce shelf-break austral Summer upwelling ${ }^{54}$. Campos et al. ${ }^{25}$ described the existence of pairs of eddies with opposite rotations south of Cabo Frio in the same way as our schematic representation, but were unable to offer an explanation for that. This persistent feature associated with high attraction $c \rho$ values $(>1,2.7$ in linear units) probably contributes for frequent revisit of drifters during the austral summer and winter (Fig. 8a,b).

Interpreting cLCS is not always a simple task so that the integration of different and independent data is needed. For that purpose, Lagrangian drifters and synthetic drifters released at specific sites have been successfully used to assess the significance of the computed $\mathrm{CLCS}^{26,27}$. Despite the seasonal variability observed in the satellite SST and model-derived EKE and CLCS, the BC flow tends to act as a transport barrier for particles. The computed PDE for 352 satellite-tracked drifters shows that they mostly concentrate in large patches along the 2000-m isobath (Fig. 8, see also Supplementary Fig. S6 for a plot of all trajectories). There is a clear spatiotemporal pattern in the distribution of trajectories, from February to May they concentrate at the northern section equatorward of $24 \mathrm{~S}$ and to the south between August and November. The prevalence of high attraction $c \rho$ values (> 1, 2.7 in linear units) also follow a similar trend as depicted from the monthly climatological attraction strength maps in Fig. 4.

The strong variability in this alongshelf current is suggested by the presence of intense eddy activity (Figs. 2a,b, $5 \mathrm{~d}-\mathrm{f}$ ), with the magnitude of EKE maxima being comparable to the MKE maxima (Fig. 2c,d). However, MKE is centered along the 2000-m isobath, while EKE maxima is centered just inshore, between the 200- and 2000-m isobaths. The location of TKE maxima is similar to the location EKE maxima with contributions from the MKE maxima, again suggesting the persistence of eddy activity (Fig. 2e,f). The deformation of climatological squeezelines crossing regions with high and low mean model SSH and aligning with surface Eulerian velocities (Fig. S5) show a consistent signature. This is most evident poleward of about 23S, where SSH gradient of low SSH between 200- and 2000-m isobaths, and high SSH offshore of the 2000-m isobath (Fig. 5a,b), seem to concentrate most of the flow horizontal shear. Nearly $30 \%$ of the 352 SVP drifters used in this study (Table 1) managed to cross regions of weak attraction (Fig. 3b, see also Fig. 7c SVP 127065; Fig. 7e iSphere 403, SVPs 78862, 2720460; Fig 7f 
SVP 62273, 2525260). In fact, the PDE of SVP drifter positions (Fig. 8) suggest that high $c \rho$ over the slope behave as a transport barrier around $200-\mathrm{m}$ isobath, the likelihood of a drifter crossing this threshold is about an order of magnitude smaller than the likelihood of not crossing. When drifters cross the $2000-\mathrm{m}$ isobath towards the $200-\mathrm{m}$ isobath, they tend to do so along a section with low $c \rho$. Similarly, drifters released inshore of the 200-m isobath tend to be confined to the shelf (Fig. 7b).

Our study domain covers two of the most important oil-producing areas of the southwest Atlantic, the Santos and Campos basins, that are responsible for $87 \%$ of total oil production in Brazil. Our results highlight the complex nature of surface transport along the $\mathrm{BC}$ and the challenges it poses to those involved in modeling oil spill trajectory as part of contingency planning and emergency response. Using examples of two different oil spill events, we show that cLCS and $c \rho$ computations provide new information that is relevant for a detailed assessment of surface transport organization. Our results for the Frade's spill agree with offshore transport that can be seen with drifting buoys (Fig. 9c), monthly SST-satellite (Fig. 9d), and the maxima EKE (Fig. 9f) offshore from the 2000-m isobath. We can see from (Fig. 9c that only one iSphere drifter (iSphere 403) and some of the synthetic drifters managed to reproduce the movement of the oil spill with the same accuracy as the transport determined by the cLCS (Fig. 9b). The usefulness of cLCS for oil spill planning and response is again demonstrated here. At the Frade's field oil spill location, the synthetic drifters and iSphere trajectories show two different transport patterns, with the oil following one of them. The fact that both transport patterns are clearly depicted by the CLCS that originate at the spill's origin further support the potential of using these Lagrangian structures to constrain the most likely oil trajectories during an emergency response. By comparing to Lagrangian patterns, we see once again that the time-averaged Eulerian velocity can be misleading regarding Lagrangian transport; the Eulerian velocity field tends to be perpendicular to the simulated and observed Lagrangian transport patterns, which are accurately depicted by cLCS (Fig. 9d, see additional examples in the supplementary information of Duran et al. $\left.{ }^{26}\right)$. In this study, we show that interpreting cLCS is not always straightforward. The interpretation, and consequently the identification of dominant transport patterns, is supported by comparisons between cLCS with time-mean Eulerian fields such as SST, SSH and TKE (Figs. 1, 2 and 5), and with SVP (e.g. Figs. 8 and 9).

Recently, a large-scale accident oiled nearly $4.000 \mathrm{~km}$ of beaches in Brazil between November 2019 and February 2020, for which the origin has not been determined so far. This gave us the unique opportunity to evaluate how the computed $c \rho$ and cLCS would have contributed to the observed oil beaching patterns, without consideration to the source of contamination. By construction, cLCS were designed to work for generic oil spills. The sequence of reported oiled sites by locals and the Brazilian government suggest that the oil spill should have originated close to the South Equatorial Current bifurcation centered around $10 \mathrm{~S}$ and $14 \mathrm{~S}^{55}$. Most of the oil dispersed as subsurface patches, yet we found good agreement between the regions of maximum values of $c \rho$ and persistent cLCS and the first and re-oiled areas in the beaches Brazilian spill (Fig. 10), suggesting which regions are most vulnerable. Comparing the sites impacted only once, and those that were re-oiled in Fig. 10 (pink and blue dots, respectively), clearly the latter tend to happen closer to $c \rho$ maxima ( $>1.3,3.6$ in linear units). The combined use of persistent $c \rho$ and cLCS with model and observational data (satellite imagery and drifting buoys) showed to be a promising tool to indicate likely oil spill trajectories and beaching sites.

\section{Summary and conclusions}

We show that by combining cLCS and $c \rho$ with SST-satellite data, model Eulerian surface velocities, mean SSH, TKE, MKE and EKE, Lagrangian drifters and synthetic drifters, it is possible to gain new insights on how surface ocean transport is organized in a complex weak WBC setting. The quasi-steady Lagrangian transport patterns in this western boundary current elegantly captured the role of persistent and recurrent eddies and meandering on the surface transport. This novel approach produced consistent results, making it possible to create an integrated representation for the role of mesoscale activity in shaping the mean flow of the BC. Accurate representation of surface flows in current systems dominated by instabilities and intense mesoscale activity is particularly challenging, e.g. reconciling Eulerian and Lagrangian views. So far, published results in the BC has provided evidences that the interaction of surface and pycnocline-level flows, together with complex bottom topography and sharp changes in the coastline orientation produce a number of persistent mesoscale features ${ }^{13,24,25}$. The time-mean Eulerian flow may not be representative of material transport, making it difficult to accurately describe at material transport the surface of the ocean. We overcome this limitation by describing the surface flow of the BC from a Lagrangian point of view, and then connecting it to Eulerian fields such as SSH, MKE and EKE. The significance of the above proposed scheme was assessed using two different oil spill events and proved to generate consistent results when compared to the observed spill trajectory and oil beaching.

\section{Data and methods}

Our domain is bounded to the north by the Abrolhos National Bank and Vitória-Trindade Seamounts and to the south by the southern limit of Cabo de Santa Marta, between 17-31S and 29-50W.

ROMS velocity data. We use daily averaged outputs from a ROMS simulation ${ }^{29,30}$ with a horizontal resolution of $1 / 36^{\circ}(\approx 3 \mathrm{~km})$ and 40 terrain-following vertical levels. The model simulation was forced every $6 \mathrm{~h}$ by the atmospheric fields obtained from the Climate Forecast System Reanalysis (CFSR) and Climate Forecast System $(\mathrm{CFSv} 2)$ with $\approx 38 \mathrm{~km}$ horizontal resolution ${ }^{56-58}$ and every 5 days lateral open boundary conditions by Simple Ocean Data Assimilation (SODA, version 3.3.1) with horizontal resolution of $0.25^{\circ}$ and 50 vertical levels ${ }^{59}$. The simulation included the inputs of two rivers (Doce and Paraíba do Sul), using the monthly runoff climatology estimated by Brazilian National Water Agency ${ }^{60}$ and river temperature by the Operational Sea Surface Temperature and Sea Ice Analysis (OSTIA) ${ }^{61}$. Tidal forcing included 08 main tidal constituents, two long periods constituents and three nonlinear harmonic constituents, extracted from the Oregon State University TOPEX/Poseidon 
Global Inverse Solution-TPXO version $8^{62}$. Our free-running simulation was integrated from January 1, 2000 to December 31, 2015, totaling 15 years of experiment, the first 3 years were discarded as spin-up, in order to use the period of model integration in which the surface energy oscillates almost periodically around a steady state ${ }^{63}$.

Lagrangian simulations. The ROMS simulations contain a built-in float algorithm that allows online tracking of passive synthetic drifters across the model domain. Particle trajectories are calculated from the Eulerian velocity fields at each baroclinic time step using the fourth-order Milne predictor and the fourth-order Hamming corrector ${ }^{64,65}$. Particle simulations were performed to cover two objectives: (1) analyze the variability behind the low-frequency Lagrangian transport patterns extracted through cLCS, and also test the information extracted through cLCS, like locations of enhanced cross-shelf transport or isolated regions, and (2) reproduce the Lagrangian transport pattern that occurred during the Frade's Field oil spill.

For the first objective, 30 synthetic drifters were launched at 28 different points in the study domain. All 28 launches, with 30 synthetic drifters each, were carried out in the austral summer and winter at the surface and include a random walk component. In the austral summer, the synthetic drifters were launched on the 1 st of December 2013 and traveled freely, in the horizontal direction, until the 28th of February 2014. While in austral winter, the synthetic drifters were launched on the 1st of June 2006 and traveled freely, in the horizontal direction, until the 30th of September 2006.

For the second objective, we launched, at a single point and once, 30 synthetic drifters at the sea surface and included a random walk component on 1st of November until 31th of December of 2011. The simulation, with the months and location of Chevron's oil spill in the Frades Field ${ }^{66}$, was performed with the oil spill data provided by Petrobras. During the oil spill six surface drifters (iSpheres) were released by Prooceano, with the permission of PetroRio SA. The iSpheres ${ }^{67,68}$ is a low cost, expendable, drifting tracking buoy developed by Metocean Data Systems. The launch of iSpheres was intended to track and monitor oil spill from Chevron.

Climatological LCS and $c \rho$. The computation of cLCS, structures organizing Lagrangian transport, follows the methodology developed by Duran et al. ${ }^{26}$. The cLCS are computed using the code presented in Duran et al. ${ }^{69}$. The sea-surface velocity data is obtained from daily outputs of a 13-year ROMS simulation. The climatology of the surface velocity was obtained by averaging each day of the time series, defining a 365 day climatology, disregarding, therefore, the leap days. Further description of the method can be found in Duran et al. ${ }^{26}$, a description of the computations and the code, can be found in Duran et al. ${ }^{69}$. Trajectories were integrated using a 4th/5th order Runge-Kutta method, with step adaptation, and cubic interpolations. The trajectory integration was done over 7 days periods ( $T=-7$ days), for each initial condition in space $\left(x_{0}\right)$ and in time $\left(t_{0}\right)$, an adequate time-scale to extract recurring or persistent transport related to mesoscale structures ${ }^{26}$. The computations use a numerical grid of $1024 \times 878$, with an auxiliary computational grid of $2.03 \mathrm{~km}$ spacing meridionally and zonally at each grid point.

Observed surface trajectories and their probability density estimate (PDE). We used 352 satellite-tracked drifters with drogues at $15 \mathrm{~m}$ depth (SVP, Surface Velocity Project ${ }^{31}$ ) whose data trajectories are distributed by NOAA'S Global Drifter Program- $\mathrm{GDP}^{70}$, with trajectories interpolated every $6 \mathrm{~h}$ and spanning 13 years of data to compute a Probability Density Estimate (PDE) of drifter trajectories. The PDE is calculated using a Probability Density Function, $\operatorname{PDF}\left(\rho, t \mid \rho_{0}, t_{0}\right)^{71,72}$, with the initial positions of each trajectory being $\rho_{0}=\left(x_{0}, y_{0}\right)$ at time time $t_{0}$, and the final position $\rho=(x, y)$ at time $t$. Regions with high incidence of trajectories were obtained with a Kernel Density Estimation ${ }^{73}$ in smoothed, approximately, with $3^{\circ} \times 3^{\circ}$ boxes at 900 points, equally spaced, calculated according to Epanechnikov ${ }^{73}$ and Silverman ${ }^{72}$. We adopted a lagrangian time scale of 3-days ${ }^{74}$ for each trajectory, based on estimated diffusion coefficient between $6 \times 10^{6}$ and $9.1 \times 10^{7} \mathrm{~cm}^{2}$ $\mathrm{s}^{-1}$ and a Lagrangian Time Scale between 1 and 5 days for SWA. The Lagrangian Integral Time Scale represents the time under which the speed at two different points in time remains autocorrelated, the interval of maximum time that the memory effect on the displacement of the particles is verified in a fluid.

For these trajectories we use a probabilistic approach, using Probability Density Estimate (PDE) of drifter trajectory movements. For the statistical analysis the drifter data was separated into three days trajectories based on the typical Lagrangian time scale for this region ${ }^{41,74}$.

Auxiliary data. The sea-surface temperature data were obtained from the global daily-SST data of the Multiscale Ultra-high Resolution (MUR) sensor ${ }^{75}$. The MUR provides data with spatial resolution of $0.01^{\circ}$, approximately $1 \mathrm{~km}$ intervals.

We estimate the distribution of kinetic energy per unit mass for the mean and eddy fields. The TKE represents the sum of the MKE, the energy of the mean circulation and the EKE, the fluctuating part of the absolute velocity $^{41,74}$. MKE, EKE and TKE were calculated as the Eqs. (1), (2) and (3):

$$
\begin{aligned}
& M K E=\frac{1}{2}\left(\overline{\mathbf{u}}^{2}+\overline{\mathbf{v}}^{2}\right) \\
& E K E=\frac{1}{2}\left(\overline{\mathbf{u}^{\prime 2}}+\overline{\mathbf{v}^{\prime 2}}\right) \\
& T K E=M K E+E K E
\end{aligned}
$$


where $\overline{\mathbf{u}}$ and $\overline{\mathbf{v}}$ are the monthly mean surface current velocities computed from the daily means, and $\mathbf{u}^{\prime}$ and $\mathbf{v}^{\prime}$ are the departures from the mean. MKE, EKE and TKE are all in $\mathrm{m}^{2} \mathrm{~s}^{-2}$.

Received: 14 July 2020; Accepted: 7 December 2020

Published online: 12 January 2021

\section{References}

1. Wiggins, S. The dynamical systems approach to lagrangian transport in oceanic flows. Annu. Rev. Fluid Mech. 37, 295-328. https ://doi.org/10.1146/annurev.fluid.37.061903.175815 (2005).

2. Assad, LPd. F., Torres Junior, A. R., Arruda, W. Z., Mascarenhas Junior, Ad. S. \& Landau, L. Volume and heat transports in the world oceans from an ocean general circulation model. Rev. Bras. Geofis. 27, 181-194. https://doi.org/10.1590/S0102-261X200900 0200003 (2009).

3. Imawaki, S., Bower, A. S., Beal, L. \& Qiu, B. Western boundary currents. Int. Geophys. 103, 305-338. https://doi.org/10.1016/ B978-0-12-391851-2.00013-1 (2013).

4. Stommel, H. A survey of ocean current theory. Deep Sea Res. 1953(4), 149-184 (1957).

5. de Oliveira, B. L. A., Netto, T. A. \& de Freitas Assad, L. P. Three-dimensional oil dispersion model in the Campos Basin, Brazil. Environ. Technol. 39, 277-287. https://doi.org/10.1080/09593330.2017.1298678 (2018).

6. da Rocha Fragoso, M. et al. A 4d-variational ocean data assimilation application for Santos Basin, Brazil. Ocean Dyn. 66, 419-434. https://doi.org/10.1007/s10236-016-0931-5 (2016).

7. D’Agostini, A., Gherardi, D. F. M. \& Pezzi, L. P. Connectivity of marine protected areas and its relation with total kinetic energy. PLOS ONE 10, e0139601. https://doi.org/10.1371/journal.pone.0139601 (2015).

8. Marta-Almeida, M. et al. Efficient tools for marine operational forecast and oil spill tracking. Mar. Pollut. Bull. 71, 139-151. https ://doi.org/10.1016/j.marpolbul.2013.03.022 (2013).

9. Romero, A., Abessa, D., Fontes, R. \& Silva, G. Integrated assessment for establishing an oil environmental vulnerability map: case study for the Santos basin Region, Brazil. Mar. Pollut. Bull. 74, 156-164. https://doi.org/10.1016/j.marpolbul.2013.07.012 (2013).

10. Peterson, R. G. \& Stramma, L. Upper-level circulation in the South Atlantic Ocean. Progr. Oceanogr. 26, 1-73. https://doi. org/10.1016/0079-6611(91)90006-8 (1991).

11. Castro, B. d., Lorenzzetti, J., Silveira, I. d. \& Miranda, L. d. Estrutura termohalina e circulação na região entre o cabo de são tomé (rj) eo chuí (rs). O ambiente oceanográfico da plataforma continental e do talude na região sudeste-sul do Brasil 1, 11-120 (2006).

12. Stramma, L. \& England, M. On the water masses and mean circulation of the South Atlantic Ocean. J. Geophys. Res. Oceans 104, 20863-20883. https://doi.org/10.1029/1999JC900139 (1999).

13. Silveira, I. d et al. Is the meander growth in the Brazil current system off Southeast Brazil due to baroclinic instability?. Dyn. Atmosph. Oceans 45, 187-207. https://doi.org/10.1016/j.dynatmoce.2008.01.002 (2008).

14. Gouveia, M. B., Gherardi, D. F., Lentini, C. A., Dias, D. F. \& Campos, P. C. Do the Brazilian sardine commercial landings respond to local ocean circulation?. PLoS ONE 12, 1-19. https://doi.org/10.1371/journal.pone.0176808 (2017).

15. Byrne, D. A., Gordon, A. L. \& Haxby, W. F. Agulhas eddies: a synoptic view using geosat ERM data. J. Phys. Oceanogr. 25, $902-917$. https://doi.org/10.1175/1520-0485(1995)025<0902:AEASVU>2.0.CO;2 (1995).

16. Scharffenberg, M. G. \& Stammer, D. Seasonal variations of the large-scale geostrophic flow field and eddy kinetic energy inferred from the topex/poseidon and jason-1 tandem mission data. J. Geophys. Res. Oceanshttps://doi.org/10.1029/2008JC005242 (2010).

17. Villas Bôas, A., Sato, O., Chaigneau, A. \& Castelão, G. The signature of mesoscale eddies on the air-sea turbulent heat fluxes in the South Atlantic Ocean. Geophys. Res. Lett. 42, 1856-1862. https://doi.org/10.1002/2015GL063105 (2015).

18. Cecilio, C., Gherardi, D., Souza, R. \& Correa-Ramirez, M. Spatio-temporal variability of the eddy kinetic energy in the South Atlantic Ocean. IEEE Geosci. Remote Sens. Lett. 11, 2010-2014. https://doi.org/10.1109/LGRS.2014.2317414 (2014).

19. Ponsoni, L. An observational study of the western boundary currents in the Indian and South Atlantic Oceans. Ph.D. Thesis, University Utrecht (2016). http://dspace.library.uu.nl/handle/1874/335229.

20. Chelton, D. B., Schlax, M. G. \& Samelson, R. M. Global observations of nonlinear mesoscale eddies. Progr. Oceanogr. 91, $167-216$. https://doi.org/10.1016/j.pocean.2011.01.002 (2011).

21. Polito, P. S. \& Sato, O. T. Do eddies ride on rossby waves?. J. Geophys. Res. Oceans 120, 5417-5435. https://doi.org/10.1002/2015J C010737 (2015).

22. Rocha, C. B., da Silveira, I. C., Castro, B. M. \& Lima, J. A. M. Vertical structure, energetics, and dynamics of the Brazil current system at 22 s-28 s. J. Geophys. Res. Oceans 119, 52-69. https://doi.org/10.1002/2013JC009143 (2014).

23. Lima, M. O. et al. An assessment of the Brazil current baroclinic structure and variability near $22 \mathrm{~s}$ in distinct ocean forecasting and analysis systems. Ocean Dyn. 66, 893-916. https://doi.org/10.1007/s10236-016-0959-6 (2016).

24. Campos, E. J., Gonçalves, J. \& Ikeda, Y. Water mass characteristics and geostrophic circulation in the South Brazil bight: summer of 1991. J. Geophys. Res. Oceans 100, 18537-18550. https://doi.org/10.1029/95jc01724 (1995).

25. Campos, E. et al. Experiment studies circulation in the western south Atlantic. Eos, Trans. Am. Geophys. Union 77, 253-259. https ://doi.org/10.1029/96EO00177 (1996).

26. Duran, R., Beron-Vera, F. J. \& Olascoaga, M. J. Extracting quasi-steady lagrangian transport patterns from the ocean circulation: an application to the Gulf of Mexico. Sci. Rep. 8, 1-10. https://doi.org/10.1038/s41598-018-23121-y (2018).

27. Gough, M. K. et al. Persistent Lagrangian transport patterns in the northwestern Gulf of Mexico. J. Phys. Oceanogr. 49, 353-367. https://doi.org/10.1175/JPO-D-17-0207.1 (2019).

28. Maslo, A., Azevedo Correia de Souza, J. M., Andrade-Canto, F. \& Rodríguez Outerelo, J. Connectivity of deep waters in the Gulf of Mexico. J. Mar. Syst. 203, https://doi.org/10.1016/j.jmarsys.2019.103267 (2020).

29. Shchepetkin, A. F. \& McWilliams, J. C. The regional oceanic modeling system (roms): a split-explicit, free-surface, topographyfollowing-coordinate oceanic model. Ocean Modell. 9, 347-404. https://doi.org/10.1016/j.ocemod.2004.08.002 (2005).

30. Shchepetkin, A. F. \& McWilliams, J. C. Correction and commentary for "ocean forecasting in terrain-following coordinates: Formulation and skill assessment of the regional ocean modeling system" by haidvogel et al., j. comp. phys. 227, pp. 3595-3624. J. Comput. Phys. 228, 8985-9000, https://doi.org/10.1016/j.jcp.2009.09.002 (2009).

31. Global Drifter Design Center and Data Buoy Co-operation Panel, USA and Switzerland. Global drifter programme barometer drifter design reference (2005). https://www.wmo.int/pages/prog/amp/mmop/documents/dbcp/Dbcp4/DBCP-4-svpb_design_ref_rev2.pdf.

32. IBAMA. Informação técnica no 7/2019-coprod/cgmac/dilic. Online (2019). https://www.ibama.gov.br/phocadownload/notas /2019/informacao_tecnica_n_7_2019.pdf. Accessed 15 Nov 2019.

33. MAR, M. Manchas de óleo no litoral do nordeste. Online (2019). https://www.marinha.mil.br/manchasdeoleo. Accessed 20 Nov 2019.

34. The Guardian. Brazil blames devastating oil spill on greek-flagged tanker. Online (2019). https://www.theguardian.com/world /2019/nov/01/brazil-blames-oil-spill-greek-flagged-tanker-venezuelan-crude.

35. Herrero, T. O petróleo ronda abrolhos. Online (2019). https://www.greenpeace.org/brasil/blog/o-petroleo-ronda-abrolhos/. Accessed 22 Nov 2019. 
36. WWF Brasil. Patrimônio da biodiversidade, abrolhos precisa ser protegido. Online (2019). https://www.wwf.org.br/?70622/Patri monio-da-biodiversidade-brasileira-Abrolhos-precisa-ser-protegido. Accessed 20 Nov 2019.

37. CI, C. Abrolhos seascape. Online (2019). https://www.conservation.org/places/abrolhos-seascape. Accessed 15 Nov 2019.

38. SAFETY4SEA. Brazil's abrolhos park in danger due to possible oil explorations. Online (2019). https://safety4sea.com/brazils-abrol hos-park-in-danger-due-to-possible-oil-explorations/. Accessed 25 Nov 2019.

39. ANP, A. Boletim da produção de petróleo e gás natural. Online (2019). http://www.anp.gov.br/arquivos/publicacoes/boletins-anp/ producao/2019-05-boletim.pdf. Accessed 03 Jul 2020.

40. Beron-Vera, F. J., Bodnariuk, N., Saraceno, M., Olascoaga, M. \& Simionato, C. Stability of the malvinas current. Chaos Interdiscip. J. Nonlinear Sci. 30, 013152. https://doi.org/10.1063/1.5129441 (2020).

41. Schmid, C., Schäfer, H., Zenk, W. \& Podestá, G. The Vitória eddy and its relation to the Brazil current. J. Phys. Oceanogr. 25, 2532-2546. https://doi.org/10.1175/1520-0485(1995)025<2532:tveair>2.0.co;2 (1995).

42. Da Silveira, I. et al. On the baroclinic structure of the Brazil current-intermediate western boundary current system at $22-23 \mathrm{~s}$. Geophys. Res. Lett.https://doi.org/10.1029/2004GL020036 (2004).

43. Calado, L., Gangopadhyay, A. \& Da Silveira, I. A parametric model for the Brazil current meanders and eddies off southeastern brazil. Geophys. Res. Lett.https://doi.org/10.1029/2006GL026092 (2006).

44. Chen, H.-H., Qi, Y., Wang, Y. \& Chai, F. Seasonal variability of sst fronts and winds on the southeastern continental shelf of Brazil. Ocean Dyn. 69, 1387-1399. https://doi.org/10.1007/s10236-019-01310-1 (2019).

45. Arruda, W. Z., Campos, E. J., Zharkov, V., Soutelino, R. G. \& da Silveira, I. C. Events of equatorward translation of the Vitoria eddy. Contin. Shelf Res. 70, 61-73. https://doi.org/10.1016/j.csr.2013.05.004 (2013).

46. Soutelino, R., Gangopadhyay, A. \& Da Silveira, I. The roles of vertical shear and topography on the eddy formation near the site of origin of the Brazil current. Contin. Shelf Res. 70, 46-60. https://doi.org/10.1016/j.csr.2013.10.001 (2013).

47. Castelao, R. M. \& Barth, J. A. Upwelling around Cabo Frio, Brazil: the importance of wind stress curl. Geophys. Res. Lett.https:// doi.org/10.1029/2005GL025182 (2006).

48. Rodrigues, R. R. \& Lorenzzetti, J. A. A numerical study of the effects of bottom topography and coastline geometry on the southeast Brazilian coastal upwelling. Contin. Shelf Res. 21, 371-394. https://doi.org/10.1016/S0278-4343(00)00094-7 (2001).

49. Calado, L., Gangopadhyay, A. \& Da Silveira, I. Feature-oriented regional modeling and simulations (forms) for the western south Atlantic: southeastern Brazil region. Ocean Modell. 25, 48-64. https://doi.org/10.1016/j.ocemod.2008.06.007 (2008).

50. Campos, E. J. Equatorward translation of the Vitoria eddy in a numerical simulation. Geophys. Res. Lett.https://doi. org/10.1029/2006GL026997 (2006)

51. Calado, L., Da Silveira, I., Gangopadhyay, A. \& De Castro, B. Eddy-induced upwelling off cape são tomé (22 s, Brazil). Contin. Shelf Res. 30, 1181-1188. https://doi.org/10.1016/j.csr.2010.03.007 (2010).

52. Palma, E. D. \& Matano, R. P. Disentangling the upwelling mechanisms of the south Brazil bight. Contin. Shelf Res. 29, 1525-1534. https://doi.org/10.1016/j.csr.2009.04.002 (2009).

53. Campos, P. C., Möller, O. O. Jr., Piola, A. R. \& Palma, E. D. Seasonal variability and coastal upwelling near Cape Santa Marta (Brazil). J. Geophys. Res. Oceans 118, 1420-1433. https://doi.org/10.1002/jgrc.20131 (2013).

54. Campos, E. J., Velhote, D. \& da Silveira, I. C. Shelf break upwelling driven by Brazil current cyclonic meanders. Geophys. Res. Lett. 27, 751-754. https://doi.org/10.1029/1999GL010502 (2000).

55. Rodrigues, R. R., Rothstein, L. M. \& Wimbush, M. Seasonal variability of the south equatorial current bifurcation in the Atlantic ocean: a numerical study. J. Phys. Oceanogr. 37, 16-30. https://doi.org/10.1175/JPO2983.1 (2007).

56. Saha, S. et al. The ncep climate forecast system reanalysis. Bull. Am. Meteorol. Soc. 91, 1015-1058. https://doi.org/10.1175/2010b ams3001.1 (2010).

57. Saha, S. et al. Ncep climate forecast system version 2 (cfsv2) monthly products. Research Data Archive at the National Center for Atmospheric Researchhttps://doi.org/10.5065/D69021ZF (2012).

58. Saha, S. et al. The ncep climate forecast system version 2. J. Clim. 27, 2185-2208. https://doi.org/10.1175/JCLI-D-12-00823.1 (2014).

59. Carton, J. A., Chepurin, G. A. \& Chen, L. SODA3: a new ocean climate reanalysis. J. Clim. 31, 6967-6983. https://doi.org/10.1175/ JCLI-D-17-0149.1 (2018).

60. Agência Nacional de Águas (Brasil). Agência nacional de Águas. Online (2018). http://biblioteca.ana.gov.br/index.asp?codigo_sophi $\mathrm{a}=76975$. Accessed 28 Aug 2019.

61. Donlon, C. J. et al. The operational sea surface temperature and sea ice analysis (ostia) system. Remote Sens. Environ. 116, 140-158. https://doi.org/10.1016/j.rse.2010.10.017 (2012).

62. Egbert, G. D. \& Erofeeva, S. Y. Efficient inverse modeling of barotropic ocean tides. J. Atmos. Ocean. Technol. 19, 183-204. https ://doi.org/10.1175/1520-0426(2002)019<0183:EIMOBO>2.0.CO;2 (2002).

63. Marchesiello, P., McWilliams, J. C. \& Shchepetkin, A. Equilibrium structure and dynamics of the California current system. J. Phys. Oceanogr. 33, 753-783. https://doi.org/10.1175/1520-0485(2003)33<753:ESADOT>2.0.CO;2 (2003).

64. Narváez, D. A. et al. Modeling the dispersal of eastern oyster (Crassostrea virginica) larvae in Delaware Bay. J. Mar. Res. 70, 381-409. https://doi.org/10.1357/002224012802851940 (2012).

65. Van Sebille, E. et al. Lagrangian ocean analysis: fundamentals and practices. Ocean Modell. 121, 49-75. https://doi.org/10.1016/j. ocemod.2017.11.008 (2018).

66. ANP, A. Relatório anual de segurança operacional das atividades de exploração e produção de petróleo e gás natural. Online (2011). http://www.anp.gov.br/images/Relatorios_SSM/Relatorio_anual_2011.pdf. Accessed 03 Jul 2020.

67. Röhrs, J. et al. Observation-based evaluation of surface wave effects on currents and trajectory forecasts. Ocean Dyn. 62, 1519-1533. https://doi.org/10.1007/s10236-012-0576-y (2012).

68. Röhrs, J. \& Christensen, K. H. Drift in the uppermost part of the ocean. Geophys. Res. Lett. 42, 10-349. https://doi. org/10.1002/2015GL066733 (2015).

69. Duran, R., Beron-Vera, F. J. \& Olascoaga, M. J. CIAM Climatological Isolation and Attraction Model-Climatological Lagrangian Coherent Structures. National Energy Technology Laboratory-Energy Data eXchange; NETL. https://doi.org/10.18141/1558781 (2019). https://bitbucket.org/rodu/clcss/src/master/.

70. Elipot, S. et al. A global surface drifter data set at hourly resolution. J. Geophys. Res. Oceans 121, 2937-2966. https://doi. org/10.1002/2016JC011716 (2016).

71. Davis, R. A., Lii, K.-S. \& Politis, D. N. Remarks on some nonparametric estimates of a density function. In Selected Works of Murray Rosenblatt, 95-100, https://doi.org/10.1214/aoms/1177728190 (Springer, Berlin, 2011).

72. Silverman, B. W. Density Estimation for Statistics and Data Analysis Vol. 26 (CRC Press, Boca Raton, 1986)

73. Epanechnikov, V. A. Non-parametric estimation of a multivariate probability density. Theory Probab. Appl. 14, 153-158. https:// doi.org/10.1137/1114019 (1969).

74. Assireu, A. T., Stevenson, M. R. \& Stech, J. L. Surface circulation and kinetic energy in the sw atlantic obtained by drifters. Contin. Shelf Res. 23, 145-157. https://doi.org/10.1016/S0278-4343(02)00190-5 (2003).

75. Chin, T. M., Vazquez-Cuervo, J. \& Armstrong, E. M. A multi-scale high-resolution analysis of global sea surface temperature. Remote Sens. Environ. 200, 154-169. https://doi.org/10.1016/j.rse.2017.07.029 (2017). 


\section{Acknowledgements}

This work has been supported by Coordenação de Aperfeiçoamento de Pessoal de Nível Superior - Brasil (CAPES) - Finance Code 001. The code for cLCS and it's acknowledgments are available at https://bitbucket.org/ rodu/clcss. We thank E. van Sebille for the initial help with float releases. We thank F. J. Beron-Vera for helpful discussions. We thank Giullian N. L. dos Reis for processing the satellite MODIS data. We thank C. L. G. Batista, A. S. Ipia for discussions and constructive comments on the text. We thank L. P. Pezzi of LOA (http://www.dsr. inpe.br/DSR/laboratorios/LOA_OBT.pdf) for authorization to use the Kerana cluster. We thank PROOCEANO (http://prooceano.com.br/site/) and PetroRio-S.A (https://petroriosa.com.br/) for the iSpheres data. We thank Petrobras (http://www.petrobras.com.br/en/) for the shape and image of MODIS referring to the oil spill occurred in November 2011. We thank IBAMA for the oil spill locations data (http://www.ibama.gov.br). We thank the developers of Regional Ocean Modeling System (https://www.myroms.org) and the Jet propulsion Laboratory for providing the Multi-scale Ultra-high Resolution (MUR) Sea Surface Temperature (SST) Analysis which is available at (https://podaac.jpl.nasa.gov/dataset/MUR-JPL-L4-GLOB-v4.1); the National Center for Atmospheric Research Staff (Eds) for CFSR and CFSV2 are available at (https://rda.ucar.edu/\#!lfd?nb $=y \& b=$ proj\&v=NCEP\%20 Climate\%20Forecast\%20System\%20Reanalysis); the SODA 3.3.1 products produced by Department of Atmospheric and Oceanic Science (https://www.atmos.umd.edu/ ocean/); the Brazilian National Water Agency from river flow data (https://www.ana.gov.br/); the Group for High Resolution SST (GHRSST) Regional/Global Task Sharing (R/GTS) framework from Operational SST and Sea Ice Analysis (OSTIA) system; the ETOPO1 Global Relief Model products produced by NOAA (https://www.ngdc.noaa.gov/mgg/global/); the altimeter products were produced by SSALTO/DUCAS and distributed by Copernicus Marine Environment Monitoring Service (https://www.encurtador.com.br/lyHRW); the OSU Tidal Data Inversion from TPXO Global Tidal Models (https ://www.tpxo.net/global); the drifter data are available from the NOAA Global Drifter Program (https://www. encurtador.com.br/imuU4). The work of RD was performed in support of the US Department of Energy's Fossil Energy, Oil and Natural Gas Research Program. It was executed by NETL's Research and Innovation Center, including work performed by Leidos Research Support Team staff under the RSS contract 89243318CFE000003. This work was funded by the Department of Energy, National Energy Technology Laboratory, an agency of the United States Government, through a support contract with Leidos Research Support Team (LRST). Neither the United States Government nor any agency thereof, nor any of their employees, nor LRST, nor any of their employees, makes any warranty, expressed or implied, or assumes any legal liability or responsibility for the accuracy, completeness, or usefulness of any information, apparatus, product, or process disclosed, or represents that its use would not infringe privately owned rights. Reference herein to any specific commercial product, process, or service by trade name, trademark, manufacturer, or otherwise, does not necessarily constitute or imply its endorsement, recommendation, or favoring by the United States Government or any agency thereof. The views and opinions of authors expressed herein do not necessarily state or reflect those of the United States Government or any agency thereof.

\section{Author contributions}

M.B.G produced the results; M.B.G and R.D conducted the experiments; M.B.G, R.D and D.F.M.G wrote the paper; R.D ceded the code and assisted in the implementation; R.T calculated EKE, MKE and TKE. All authors analysed the results and reviewed the manuscript.

\section{Competing interests}

The authors declare no competing interests.

\section{Additional information}

Supplementary Information is available for this paper at https://doi.org/10.1038/s41598-020-79386-9.

Correspondence and requests for materials should be addressed to R.D.

Reprints and permissions information is available at www.nature.com/reprints.

Publisher's note Springer Nature remains neutral with regard to jurisdictional claims in published maps and institutional affiliations.

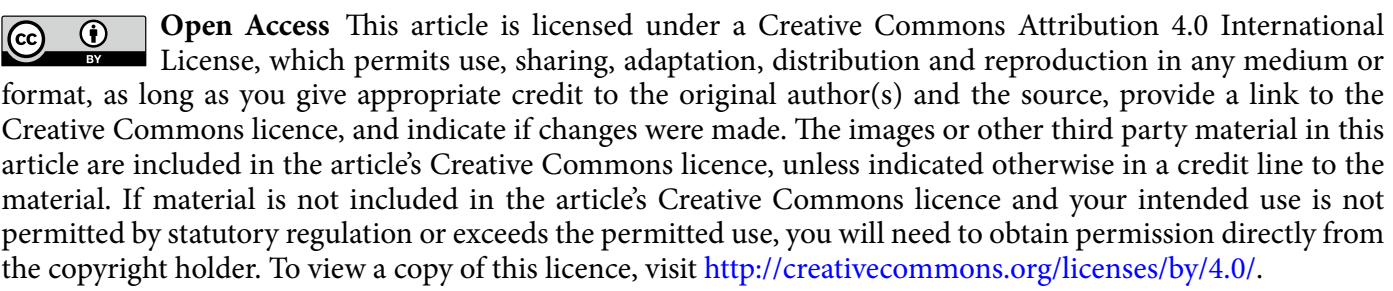

(c) The Author(s) 2021 